\title{
The Blood-Brain Barrier
}

\author{
Richard Daneman ${ }^{1}$ and Alexandre Prat ${ }^{2}$ \\ ${ }^{1}$ Departments of Neuroscience and Pharmacology, University of California, San Diego, San Diego, \\ California 92093 \\ ${ }^{2}$ Department of Neuroscience, Université de Montréal, Montréal, Quebec H2X 0A9, Canada \\ Correspondence: rdaneman@ucsd.edu
}

\begin{abstract}
Blood vessels are critical to deliver oxygen and nutrients to all of the tissues and organs throughout the body. The blood vessels that vascularize the central nervous system (CNS) possess unique properties, termed the blood-brain barrier, which allow these vessels to tightly regulate the movement of ions, molecules, and cells between the blood and the brain. This precise control of CNS homeostasis allows for proper neuronal function and also protects the neural tissue from toxins and pathogens, and alterations of these barrier properties are an important component of pathology and progression of different neurological diseases. The physiological barrier is coordinated by a series of physical, transport, and metabolic properties possessed by the endothelial cells (ECs) that form the walls of the blood vessels, and these properties are regulated by interactions with different vascular, immune, and neural cells. Understanding how these different cell populations interact to regulate the barrier properties is essential for understanding how the brain functions during health and disease.
\end{abstract}

B lood vessels convey blood from the heart to each tissue and organ throughout the body, which is essential to deliver oxygen and nutrients to the tissues, remove carbon dioxide and metabolic waste from tissues, convey hormonal signaling among tissues, as well as mediate the interaction of the peripheral immune system with each tissue. The vascular tree is comprised of arteries and arterioles, which deliver blood to the tissues, the capillary bed, which is essential for gas and nutrient exchange within tissues, and venules and veins, which drain blood from tissues. Each segment has different properties depending on where they are in the vascular tree as well as which organ they vascularize. In particular, the microvasculature, made up of the capillaries and postcapillary venules, has different properties to meet the unique requirements of the tissue they vascularize.

There are three main structural classes of capillaries. Continuous nonfenestrated capillaries of the skin and lung are joined together by cellular junctions, have a complete basement membrane (BM), and lack fenestra (pores) in their plasma membrane. Continuous fenestrated vessels of the intestinal villi and endocrine glands have a similar continuous structure but contain diaphragmed fenestra throughout their membrane. Discontinuous capillaries in the liver have large gaps throughout the cell and have an incomplete BM. These classes of capillaries differ greatly in their regulation of movement of

Editors: Ben A. Barres, Marc R. Freeman, and Beth Stevens

Additional Perspectives on Glia available at www.cshperspectives.org

Copyright (C) 2015 Cold Spring Harbor Laboratory Press; all rights reserved; doi: 10.1101/cshperspect.a020412

Cite this article as Cold Spring Harb Perspect Biol 2015;7:a020412 
solutes between the blood and the tissues, with continuous fenestrated capillaries being the most restrictive, and discontinuous being the least restrictive (Aird 2007a,b).

The blood-brain barrier (BBB) is a term used to describe the unique properties of the microvasculature of the central nervous system (CNS). CNS vessels are continuous nonfenestrated vessels, but also contain a series of additional properties that allow them to tightly regulate the movement of molecules, ions, and cells between the blood and the CNS (Zlokovic 2008; Daneman 2012). This heavily restricting barrier capacity allows BBB ECs to tightly regulate CNS homeostasis, which is critical to allow for proper neuronal function, as well as protect the CNS from toxins, pathogens, inflammation, injury, and disease. The restrictive nature of the $\mathrm{BBB}$ provides an obstacle for drug delivery to the CNS, and, thus, major efforts have been made to generate methods to modulate or bypass the BBB for delivery of therapeutics (Larsen et al. 2014). Loss of some, or most, of these barrier properties during neurological diseases including stroke, multiple sclerosis (MS), brain traumas, and neurodegenerative disorders, is a major component of the pathology and progression of these diseases (Zlokovic 2008; Daneman 2012). BBB dysfunction can lead to ion dysregulation, altered signaling homeostasis, as well as the entry of immune cells and molecules into the CNS, processes that lead to neuronal dysfunction and degeneration.

\section{CELLS OF THE BBB}

Blood vessels are made up of two main cell types: ECs that form the walls of the blood vessels, and mural cells that sit on the ablumenal surface of the EC layer. The properties of the BBB are largely manifested within the ECs, but are induced and maintained by critical interactions with mural cells, immune cells, glial cells, and neural cells, which interact in the neurovascular unit (Fig. 1).

\section{Endothelial Cells}

Endothelial cells (ECs) are mesodermally derived modified simple squamous epithelial cells that form the walls of blood vessels. The diameter of large arteries and veins can be made up of dozens of ECs, whereas the smallest capillary is formed by a single EC folding onto itself to form the lumen of the vessel (Aird 2007a,b). These CNS microvascular ECs are extremely thin cells that are 39\% less thick than muscle ECs, with a distance of less than a quarter of a micron separating the lumenal from the parenchymal surface (Coomber and Stewart 1985).

CNS ECs have unique properties compared with ECs in other tissues that allow them to tightly regulate the movement of ions, molecules, and cells between the blood and the brain. CNS ECs are held together by tight junctions (TJs), which greatly limit the paracellular flux of solutes (Reese and Karnovsky 1967; Brightman and Reese 1969; Westergaard and Brightman 1973). CNS ECs undergo extremely low rates of transcytosis as compared with peripheral ECs, which greatly restricts the vesicle-mediated transcellular movement of solutes (Coomber and Stewart 1985). This tight paracellular and transcellular barrier creates a polarized cell with distinct lumenal and ablumenal membrane compartments such that movement between the blood and the brain can be tightly controlled through regulated cellular transport properties (Betz and Goldstein 1978; Betz et al. 1980).

There are two main categories of transporters expressed by CNS ECs. The first are efflux transporters, which are polarized to the lumenal surface and transport a wide variety of lipophilic molecules that could otherwise diffuse across the cell membrane, toward the blood (CordonCardo et al. 1989; Thiebaut et al. 1989; Loscher and Potschka 2005). The second are highly specific nutrient transporters that facilitate the transport of specific nutrients across the $\mathrm{BBB}$ into the CNS, as well as removal of specific waste products from the CNS into the blood (Mittapalli et al. 2010). CNS ECs contain higher amounts of mitochondria compared to other ECs (Oldendorf et al. 1977), which is thought to be critical to generate ATP to drive the ion gradients critical for transport functions. CNS ECs also express an extremely low level of leukocyte adhesion molecules (LAMs), as compared with ECs in other tissues greatly limiting 

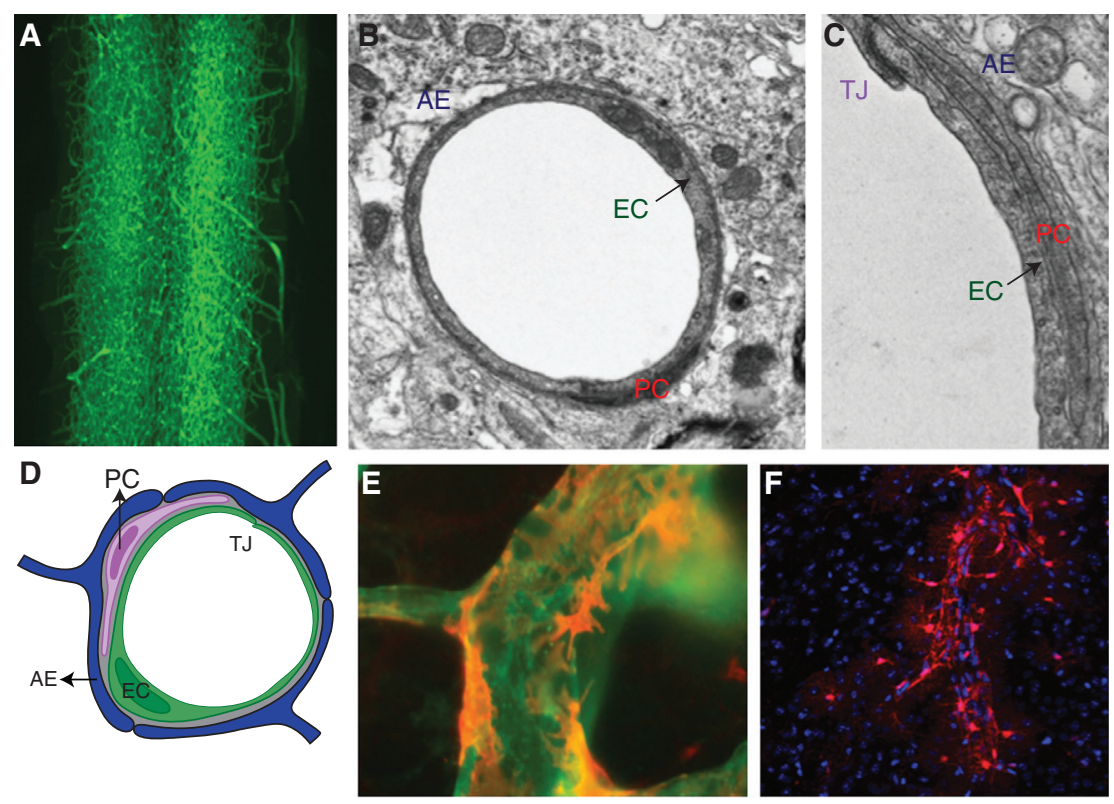

Figure 1. Components of the BBB. (A) Vascular cast of a spinal cord showing density of the CNS vascular network. (B) Electron micrograph (EM) of a cross section of a CNS vessel depicting a relationship among endothelial cells (ECs), pericytes (PCs), and astrocytes. $(C)$ Magnified EM of ECs depicting a relationship among ECs (with tight junctions [TJ]), PCs, basement membranes (BMs), and astrocyte endfeet (AE). $(D)$ Schematic representation of the cell types within the neurovascular unit. $(E)$ Immunofluorescence micrograph depicting relationship of PCs (red) with ECs (green). (F) Micrograph depicting relationship of astrocytes (red-labeled with GFAP-cre; Rosa-tdTomato) with blood vessels (unstained). Astrocytes extend processes that ensheath the blood vessels, such that the outline of the blood vessels can be visualized by the endfeet of these processes (courtesy of Matthew Boisvert and Nicola Allen).

the amount of immune cells that enter the CNS (Henninger et al. 1997; Aird 2007a; Daneman et al. 2010a). In addition, there is thought to be differential vascular metabolism in CNS ECs generating a barrier by altering the physical properties of molecules, which can change their reactivity, solubility, and transport properties. The combination of physical barrier properties (TJs, low transcytosis), molecular barrier properties (efflux transporters, specific metabolism, low LAMs), as well as specific transporters to deliver required nutrients, allows the ECs to tightly regulate CNS homeostasis.

A major question remains whether the $\mathrm{BBB}$ in different regions of the brain possess unique properties required for the function of the local neural circuitry. For instance, localized transport of specific nutrients could be important for the development or functions of specific subclasses of neurons. Although most regions of the CNS are vascularized by capillaries that contain BBB properties, specific nuclei adjacent to the third and fourth ventricles, including the subfornical organ, area postrema, pineal gland, and median eminence, contain vessels that have a much greater passive permeability (Ufnal and Skrzypecki 2014). The capillaries of these circumventricular organs are continuous fenestrated vessels, with a high permeability to solutes. This high permeability is important for the functions of these nuclei, which either sense blood solute concentrations or secrete molecules into the blood.

\section{Mural Cells}

Mural cells include vascular smooth muscle cells that surround the large vessels and pericytes, which incompletely cover the endothelial walls of the microvasculature. Pericytes (PCs) 
are cells that sit on the ablumenal surface of the microvascular endothelial tube, and are embedded in the vascular BM (Sims 1986). A difficulty in studying PCs is the lack of a specific marker that is expressed uniquely by PCs, and, thus, these cells are often confused with other cells that sit in the perivascular space (Armulik et al. 2011). Currently, the most widely accepted molecular identifier of CNS PCs is positive reactivity to both PDGFR- $\beta$ and NG2; but other markers, including Anpep (CD13), desmin, Rgs5, Abcc9, Kcnj8, Dlk, and Zic1, have all been used to identify PCs, with none being perfect identifiers of this cell type (Armulik et al. 2011). Pericytes extend long cellular processes along the ablumenal surface of the endothelium that can often span several EC bodies. These cells contain contractile proteins, and have the ability to contract to control the diameter of the capillary (Peppiatt et al. 2006; Hall et al. 2014). Although these cells line the endothelial tube, most of the cell body and processes do not touch the endothelium, but are separated by the BM they are embedded within. The processes do form cellular adhesions with the endothelium at discrete points, described as peg-and-socket junctions, and are mediated by the adhesion molecule N-cadherin (Gerhardt et al. 2000). In addition, other pericyte-endothelial cellular adhesions have been identified including adhesion plaques, gap junctions, and tight junctions (Courtoy and Boyles 1983; Cuevas et al. 1984; Larson et al. 1987; Diaz-Flores et al. 2009).

CNS PCs have been shown to have unique properties compared to PCs in other tissues. CNS PCs are derived from the neural crest, in contrast with PCs in many peripheral tissues, which are derived from the mesoderm (Majesky 2007). In addition, CNS microvasculatures have the highest CNS PCs coverage of any tissue, with an endothelial:pericyte ratio estimated between $1: 1$ and 3:1, whereas the muscle has a ratio of 100:1 (Shepro and Morel 1993). Pericytes play important roles in regulating angiogenesis, deposition of extracellular matrix, wound healing, regulating immune cell infiltration, and regulation of blood flow in response to neural activity, and reports suggest that they also can be multipotent stem cells of the CNS (Armulik et al.
2011). In addition, these cells have been shown to be important for regulating the formation of the BBB during development, as well as maintaining its function in adulthood and aging (Armulik et al. 2010; Daneman et al. 2010b). One of the major questions in pericyte biology is whether there are different subsets of PCs that may have different functions. Owing to the lack of defining markers, it remains unclear whether all of the different functions attributed to PCs are performed by all of the same cells, by different subsets of PCs, or even by nonpericyte cells that sit adjacent to the vasculature. The identification of new PC-specific markers, as well as the potential identification of markers of subsets of PCs will aid in clearing up these issues.

\section{Basement Membrane}

The vascular tube is surrounded by two BMs, the inner vascular BM and the outer parenchymal BM, also called the vascular glia limitans perivascularis (Del Zoppo et al. 2006; Sorokin 2010). The vascular BM is an extracellular matrix secreted by the ECs and PCs, whereas the parenchymal BM is primarily secreted by astrocytic processes that extend toward the vasculature. These BMs are comprised of different secreted molecules including type IV collagens, laminin, nidogen, heparin sulfate proteoglycans, and other glycoproteins. The vascular and parenchymal BMs have a different composition, for instance, the former is made up of laminins $\alpha 4$ and $\alpha 5$, whereas the latter contains laminins $\alpha 1$ and $\alpha 2$ (Wu et al. 2009; Sorokin 2010). These BMs provide an anchor for many signaling processes at the vasculature, but also provide an additional barrier for molecules and cells to cross before accessing the neural tissue. Disruption of these BMs by matrix matalloproteinases is an important component of BBB dysfunction and leukocyte infiltration that is observed in many different neurological disorders.

\section{Astrocytes}

Astrocytes are a major glial cell type, which extend polarized cellular processes that ensheath either neuronal processes or blood vessels (Abbott et al. 2006). The endfeet of the basal process 
almost completely ensheath the vascular tube, and contain a discrete array of proteins including dystroclycan, dystrophin, and aquaporin 4. The dysroglycan-dystrophin complex is important to link the endfeet cytoskeleton to the BM by binding agrin (Noell et al. 2011; Wolburg et al. 2011). This linkage coordinates aquaporin 4 into orthogonal arrays of particles, which is critical for regulating water homesostasis in the CNS. Astrocytes provide a cellular link between the neuronal circuitry and blood vessels. This neurovascular coupling enables astrocytes to relay signals that regulate blood flow in response to neuronal activity (Attwell et al. 2010; Gordon et al. 2011). This includes regulating the contraction/dilation of vascular smooth muscle cells surrounding arterioles as well as PCs surrounding capillaries. Astrocytes have been identified as important mediators of BBB formation and function because of the ability of purified astrocytes to induce barrier properties in nonCNS blood vessels in transplantation studies (Janzer and Raff 1987), as well as induce barrier properties in cultured ECs in in vitro coculture paradigms (Abbott et al. 2006). One issue with these studies is that the astrocytes are often cultured from neonatal rodent brains and go through many rounds of cell division, suggesting that these studies are analyzing progenitor cells as opposed to mature astrocytes. Recent data analyzing the $\mathrm{BBB}$ in dissected rodent embryos suggest that the $\mathrm{BBB}$ is formed before astrocyte generation and ensheathment of the vasculature (Daneman et al. 2010b), and, thus, these cells do not play a role in the initial induction of the BBB. The identification of astrocytesecreted factors that do regulate $\mathrm{BBB}$ function suggests that mature astrocytes modulate and maintain the barrier once it is formed.

\section{Immune Cells}

CNS blood vessels interact with different immune cell populations both within the blood as well as within the CNS. The two main cell populations within the CNS are perivascular macrophages and microglial cells. Perivascular macrophages are monocyte lineage cells that sit on the ablumenal side of the vascular tube commonly found in the Virchow-Robin space, a small fluid filled canal that lines the ablumenal surface of the veins and arteries that enter/ leave the CNS (Hickey and Kimura 1988; Polfliet et al. 2001). These cells are derived from bloodborne progenitors, and chimera experiments suggest that they are able to cross the $\mathrm{BBB}$ and can be $80 \%$ replaced within 3 mo (Unger et al. 1993; Vass et al. 1993; Williams et al. 2001). These cells provide a first line of innate immunity by phagocytosing cellular debris. Microglial cells are resident CNS parenchymal immune cells that are derived from progenitors in the yolk sac and enter the brain during embryonic development (Ginhoux et al. 2010). These cells are involved in regulating neuronal development, innate immune response, and wound healing, and can act as antigen-presenting cells in adaptive immunity (Streit et al. 2005; Ajami et al. 2007). In addition, different blood-borne immune cell populations, including neutrophils, T cells, and macrophages, can interact with CNS vessels when activated and are thought to regulate $\mathrm{BBB}$ properties in response to infection, injury, and disease by releasing reactive oxygen species that can increase vascular permeability (Persidsky et al. 1999; Hudson et al. 2005). Identifying the mechanisms by which both the immune cells and the BBB become "activated" to interact may be important in deciphering the mechanisms by which the $\mathrm{BBB}$ is disrupted during different neurological diseases.

\section{MOLECULES OF THE BBB}

The discovery of molecules expressed by CNS ECs has led to the identification of important structural and transport components of the BBB (Fig. 2) (Li et al. 2001, 2002; Enerson and Drewes 2006; Cayrol et al. 2008; Daneman et al. 2009, 2010a; Ohtsuki et al. 2014). Recently, the use of large-scale genomic and proteomic experimental approaches has provided greater detail and understanding of the molecular biology of the BBB. Use of acutely purified microvascular fragments, acutely purified ECs, and cultured ECs combined with microarrary technology, RNA sequencing, and mass spec- 


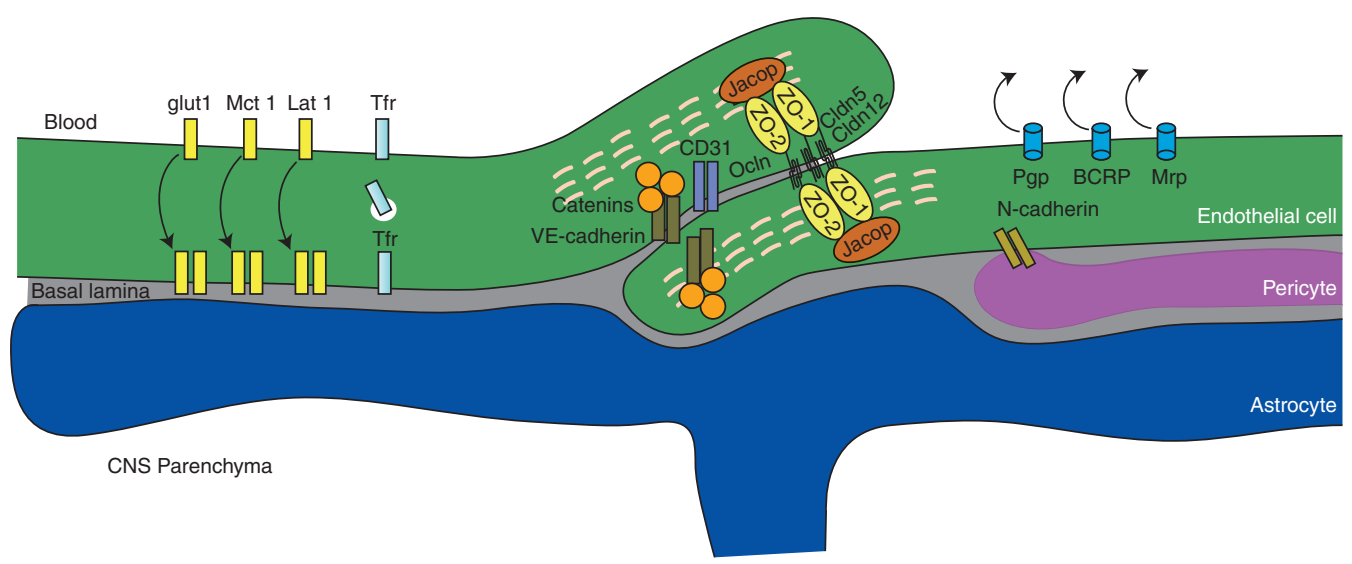

Figure 2. Schematic representation of molecules of the BBB. CNS, central nervous system; VEcad, VE cadherin.

troscopy proteomic analysis have enabled largescale gene expression comparisons of CNS ECs with neural cells as well as ECs from other tissues. In particular, comparison of the molecular differences between CNS ECs and ECs from nonneural tissues has provided an understanding of the unique molecular composition of the BBB.

\section{Tight Junctions}

CNS ECs are held together by TJs, which create a high-resistance paracellular barrier to molecules and ions, polarizing the luminal and ablumenal compartments. Most of what is known about TJs is from work on ECs, which have identified that these cellular adhesions are formed on the apical part of the lateral membrane by homotypic and heterotypic interactions of transmembrane molecules that are linked to the cytoskeleton through interactions with cytoplasmic adaptors. The strength of the junctions varies greatly depending on the tissue in which they are found, and work in cell culture suggests that they have a size-selective permeability to uncharged molecules of up to $4 \mathrm{~nm}$, and then low permeability to larger molecules (Van Itallie and Anderson 2006; Van Itallie et al. 2008). This suggests that the TJs form a 4-nm pore and that larger molecules would pass through discontinuities in the junctions.

The transmembrane molecules include claudins, occludins, and JAMs (Furuse 2010).
Claudins are a class of more than 25 different family members that are tetraspanins characterized by a W-GLW-C-C domain in the first extracellular loop (Gupta and Ryan 2010). Evidence in vitro suggests that claudins are essential for the paracellular barrier formation. Expression of claudins is sufficient to form TJ strands in fibroblasts, and disruption of claudins decreases the paracellular barrier properties of canine kidney cells (Furuse et al. 1998, 2001; Van Itallie et al. 2001; Amasheh et al. 2005; Hou et al. 2006). Work with chimeric claudins has shown that amino acid residues in the first extracellular loop define the size and charge selectivity of the pore within the cellular junction, and, thus, the composition of the claudins within a given cell can determine the permeability of the paracellular barrier (Colegio et al. 2003). Different claudin family members are expressed by different epithelial barriers in different tissues, and mouse knockouts have shown that specific family members are essential for specific barriers (cldn 1 epidermal barrier, cldn 16 kidney epithelia, cldn11 CNS myelin, cldn 19 peripheral myelin), many of which have been associated with human disease (Gow et al. 1999; Furuse et al. 2002; Hadj-Rabia et al. 2004; Knohl and Scheinman 2004; Miyamoto et al. 2005; Hampson et al. 2008). Claudin-5 has been shown to be highly expressed by CNS ECs, and mice that lack claudin-5 have a sizeselective leak of the BBB (Morita et al. 1999; Nitta et al. 2003). In addition, other claudins, 
including cldn 12 and cldn 3 , have been identified at the BBB (Nitta et al. 2003; Liebner et al. 2008; Daneman et al. 2010a).

Occludin is a tetraspanin expressed by epithelial cells and CNS ECs, an in vitro culture experiment disrupting occludin homotypic interactions suggest that it is important for the resistance of the barrier (Balda et al. 1996; McCarthy et al. 1996; Wong and Gumbiner 1997). Occludin is highly enriched in CNS ECs compared with ECs in nonneural tissues, indicating that it may be an important component of the barrier. Occludin-deficient mice, however, are shown to have a normal high-resistance epithelial barrier and a functioning BBB. These mice do have calcification of the CNS suggesting that perhaps occludin specifically regulates calcium flux across the BBB (Saitou et al 2000). JAMs are immunoglobulin superfamily members that form homotypic interactions at tight junctions in epithelial cells and ECs. JAMs have been shown to regulate leukocyte extravasation as well as paracellular permeability (Martin-Padura et al. 1998; Johnson-Leger et al. 2002; Ludwig et al. 2005). In particular, JAM4 has been identified at the BBB in mice (Daneman et al. 2010a). Recently, it has been shown that unique molecular components are required to seal the paracellular barrier at the contact points of three cells. These tricellular junctional complexes are made up of lipolysis-stimulated receptor (LSR), which is required to localize marveld2 to tricellular adhesions (Masuda et al. 2011). It remains unclear what the nature of the size/charge-selective pore is formed by the specific composition tight junction proteins expressed by CNS ECs, and whether the permeability of this pore is static or whether it is dynamically altered in response to neuronal activity.

The transmembrane adhesion complexes are linked to the cytoskeleton through a series of cytoplasmic adaptors including ZO-1, ZO-2, Cingulin, Jacop, MAGIs, and MPPs (Van Itallie and Anderson 2013). In addition, the TJs interact with basal adherens junctions (AJs), which connect all ECs and are made up of vascular endothelial (VE)-cadherin and platelet EC adhesion molecules (PECAM)1, and are linked to the cytoskeleton by catenins. Interestingly, many of the TJ proteins identified, including cldn5, cldn12, ZO-1, and ZO2, appear to be expressed by ECs in all tissues. Thus, a major question is why only CNS ECs form this tight barrier and not ECs in other tissues. Transcriptional analysis comparing CNS ECs with peripheral ECs suggests that several cytoplasmic adaptors, including jacop and MPP7, as well as tricellular TJ molecules, LSR and marveld2 (Daneman et al. 2010a), are enriched at the BBB suggesting that these molecules may be critical for this barrier formation.

\section{Transporters}

CNS ECs are highly polarized cells that have distinct lumenal and ablumenal compartments. The low permeability of the paracellular junctions allows the transport properties of the cells to control the movement of ions and molecules between the blood and the brain. There are two main types of transporters expressed by CNS ECs: efflux transporters and nutrient transporters. Current work to elucidate the full array of transporters and their substrates is highly sought after both to understand the external requirements for brain metabolism and function, but also to identify targets to aid in drug delivery across the BBB.

Efflux transporters, including Mdr1, BCRP, and MRPs, use the hydrolysis of ATP to transport their substrates up their concentration gradient (Ha et al. 2007). Many of these transporters are localized to the lumenal surface and transport a wide array of substrates into the blood compartment. This wide substrate diversity allows these transporters to provide a barrier to many small lipophilic molecules, which would otherwise passively diffuse through the EC membrane. Mdr1, also called P-glycoprotein, has been widely studied in this context, and knockout mice show an increase in a wide variety of small lipophilic drugs entering the brain, as well as endogenous molecules (Schinkel et al. 1994, 1995, 1996). Up-regulation of Mdr1 has also been associated with drug-resistant epilepsy and tumors (Potschka et al. 2001; Abbott et al. 2002). An important avenue of research uses structural modeling to predict 
substrates of these efflux transporters to develop therapeutics that can avoid efflux and, thus, gain entry to the CNS. In addition, developing inhibitors of these efflux transporters is an ongoing research avenue to aid in delivery of small molecule compounds to the CNS. Interestingly, not much is known about the endogenous molecules that are effluxed by these transporters, how this is important to regulate brain function, and whether inhibitors would alter the tissue distribution of important endogenous molecules.

Nutrient transporters facilitate the movement of specific nutrients down their concentration gradient. CNS ECs express a wide variety of these transporters to deliver very specific nutrients across the physical barrier of the CNS ECs into the CNS parenchyma. Many of these belong to the solute carrier class of facilitated transporters, including slc2a 1 (glucose), slc16a1 (lactate, pyruvate), slc7al (cationic amino acids), and slc7a5 (neutral amino acids, L-DOPA) (Zlokovic 2008; Daneman 2012). Slc2a1, also called glut1, has been largely studied for its role in providing the CNS with glucose. Expression of this transporter is highly enriched in CNS ECs compared with ECs in nonneural tissues, and it facilitates the transport of glucose down its concentration gradient from the blood into the brain (Cornford et al. 1994). In humans, Glut1 deficiency leads to an epileptic syndrome that is treated by being fed a highketone diet (De Vivo et al. 1991, 2002). In addition, CNS ECs express a variety of different receptor-mediated transport systems, including the transferrin receptor (transferrin/iron), Ager (amyloid), and low-density receptor-related lipoprotein (LRP)1/LRP8. Many of these transport systems are being targeted as Trojan horses to aid in drug delivery to the CNS. Although most of these transporters provide nutrients from the blood to the brain (slc2a1, slc16a1, slc7a5, Tfr), several are also important for removing waste products from the brain (Ager). A complete characterization of BBB transporters, their substrates, and their direction of transport is critical to determine the external nutrient requirements of the CNS and how the BBB mediates the interaction between the blood and the CNS. Recently, systemic proteins have been im- plicated in regulating neurogenesis differently in youth and during aging (Villeda et al. 2011, 2014; Katsimpardi et al. 2014); however, it remains unclear whether this is because of specific transport, localized permeability of the BBB, or nonspecific passive movement of small amounts of systemic factors.

\section{Transcytosis}

In CNS ECs, the rate of transcytosis is dramatically lower than in ECs in nonneural tissues but is up-regulated as a major component of $\mathrm{BBB}$ dysfunction during injury and disease. Transcytosis through ECs is mediated through caveolin-based vesicle trafficking. Caveolin-1 is expressed by all ECs and is up-regulated at the BBB following traumatic brain injury (Liu et al. 2010; Zhao et al. 2011; Gu et al. 2012). Plasmalemma vesicle-associated protein (PLVAP) expression is enriched in peripheral ECs compared with CNS ECs, and has been implicated in vesicle trafficking, formation of fenestra, and leukocyte extravasation in these "leaky" vascular beds. This molecule is also up-regulated in CNS ECs in a variety of diseases in which there is BBB leakage (Shue et al. 2008; Keuschnigg et al. 2009). Therefore, lack of PLVAP in healthy CNS ECs appears to be important for limiting permeability.

\section{Leukocyte Adhesion Molecules (LAMs)}

In the healthy CNS, there is an extremely low level of immune surveillance, with an almost complete lack of neutrophils and lymphocytes within the parenchyma. Entry of a leukocyte from the blood into a tissue is a multiple-step process that includes rolling adhesion, firm adhesion, and extravasation. This requires a series of different leukocyte adhesion molecules, including selectins (E-selectin, P-selectin) for rolling adhesion and immunoglobulin family members for firm adhesion (Huang et al. 2006; Aird 2007b). The expression of these adhesion molecules is much lower in CNS ECs than in peripheral ECs but is elevated during neuroinflammatory diseases, such as stroke and MS (Henninger et al. 1997; Huang et al. 2006; Engelhardt 2008; Daneman et al. 2010a). Interest- 
The Blood-Brain Barrier

ingly, different subsets of inflammatory cells are observed infiltrating the CNS in different diseases. For instance, in MS, there is infiltration of $\mathrm{T}$ cells, $\mathrm{B}$ cells, neutrophils, and macrophages at sites of active lesions, whereas in stroke, there are neutrophil and macrophage infiltrates but lymphocytes are largely excluded. An important question is whether each cell has a different mechanism for crossing the $\mathrm{BBB}$, and whether the discrimination is done at the level of the activated $\mathrm{BBB}$ or the activated immune cell.

\section{Other Components of the BBB}

Large-scale genomic and proteomic approaches have identified signaling cascades that are turned on in CNS ECs. In particular, Wnt $/ \beta$ catenin signaling through Lef1, as well as Sonic hedgehog signaling through Gli have been shown to be important for regulating the formation and function of the BBB (Liebner et al. 2008; Stenman et al. 2008; Daneman et al. 2009; Alvarez et al. 2011a). In addition, vascular metabolism has been implicated in regulating barrier properties of CNS vasculature by metabolizing potential toxins or altering the properties of molecules (Fig. 1). Specific enzymes, including carbonic anhydrase IV and $\gamma$-glutamyl transpeptidase, have been identified as enriched in CNS vessels compared with vessels from nonneural tissues (Orlowski et al. 1974; Ghandour et al. 1992).

Large-scale genomic and proteomic approaches have provided invaluable resources in understanding the gene expression of the $\mathrm{BBB}$, but work still needs to be done to identify which of these BBB-enriched genes are important for each aspect of the $\mathrm{BBB}$, whether there is heterogeneity of these genes at different segments of the vascular tree and in different brain regions, and whether the expression and function of each protein is dynamically regulated by neuronal function, stress, or diet. In addition, work expanding beyond genomics is aimed at identifying the proteomics, miRNAs, noncoding RNAs, lipids, metabolomics, epigenetics, and other regulatory steps that are important for $\mathrm{BBB}$ formation and function.

\section{REGULATION OF THE BBB FORMATION AND HOMEOSTASIS}

Although key properties of the BBB are manifested within the ECs, important transplantation studies have shown that they are regulated by interactions with the microenvironment of the CNS (Stewart and Wiley 1981; Janzer and Raff 1987). The BBB is not one physiology, but a series of physiological properties that either need to be induced (TJs, transporters, metabolic enzymes) or inhibited (transcytosis, LAMs) in CNS ECs. Recent work has dissected the cellular and molecular mechanisms that regulate this process, and have identified that it is a complex process of induction and maintenance signaling interactions among CNS ECs and PCs, astrocytes, and immune cells.

\section{Regulation of Barrier Properties during Angiogenesis}

Recent work in genetic mouse models has shown that there is a unique angiogenic program driving vessel formation in the CNS regulated by $\mathrm{Wnt} / \beta$-catenin that also induces specific barrier properties in CNS ECs (Liebner et al. 2008; Stenman et al. 2008; Daneman et al. 2009). Comparative microarray analysis has identified that effectors of Wnt $/ \beta$-catenin signaling, including Lef1, Apcdd1, and tnfrsf19, are enriched CNS ECs compared to ECs in peripheral organs (Daneman et al. 2009, 2010a). Transgenic reporter mice have confirmed that Wnt/ $\beta$-catenin signaling is activated in CNS ECs during embryonic angiogenesis (Liebner et al. 2008; Stenman et al. 2008; Daneman et al. 2009). Different Wnt ligands are secreted by neural stem cells and neural progenitors in spatially distinct regions, notably Wnt7a and Wnt7b in ventral regions and Wnt1, Wnt3, Wnt 3a, and Wnt4 in dorsal regions (Stenman et al. 2008; Daneman et al. 2009). Disruption of Wnt signaling in all ECs by conditional depletion of $\beta$-catenin leads to widespread CNS angiogenic defects with overtly normal blood vessel formation in peripheral tissues. These defects include a thickening of the vascular plexus, which contains endothelial progenitors, a loss of capillary beds, 
and the formation of hemorrhagic vascular malformations, which together suggest that Wnt is a migration signal driving vessels into the CNS (Stenman et al. 2008; Daneman et al. 2009). These phenotypes were also observed following deletion of neural Wnts (Wnt7a/7b), demonstrating that the CNS angiogenic program requires Wnt as well as $\beta$-catenin. This CNSspecific angiogenic program was also shown to induce the expression of nutrient transporters, such as glut1, as well as the specific tight junction molecules like claudin-3 (Liebner et al. 2008; Stenman et al. 2008; Daneman et al. 2009). Taken together, these data suggest that specific properties of the BBB are induced as vessels invade the CNS by a unique angiogenic program. Different Wnt ligands and Fzd receptors are expressed in spatially distinct regions and appear to be important for the regulation of CNS angiogenesis and BBB formation in those regions. One interesting receptor/ligand pair is Norrin/Fzd4, which is required for the formation of the retinal vasculature. Norrin is a transforming growth factor (TGF) $\beta$ family member with no homology with Wnt ligands, which is able to activate Fzd4 and induce canonical Wnt signaling. Loss of Norrin or Fzd4 produces major retinal vascular defects including a reduction in endothelial proliferation, vascular malformations, crossing of arteries and veins, a loss of venous fate, and leakiness of the bloodretinal barrier (Xu et al. 2004; Ye et al. 2010; Wang et al. 2012). Fzd4 mutants also have regional-specific BBB defects in the cerebellum, spinal cord, olfactory bulb but not the cortex, striatum, or hypothalamus. The more widespread phenotype of Fzd4 mutants suggests that it may also be activated by other ligands. Use of genetic mosaics has shown that Fzd4 is required cell-autonomously for sealing the BBB, and the Fzd4-deficient ECs have a loss of claudin-5 and an increase in PLVAP (Wang et al. 2012). Interestingly, deletion of Fz4 in adults leads up-regulation of PLVAP, loss of claudin-5, and leakage of the BBB, whereas reintroduction of Norrin to Norrin-deficient retinas leads to sealing of BBB properties (Wang et al. 2012). These data suggest that canonical Wnt signaling is not only required for $\mathrm{BBB}$ induction, but that also for maintenance of the BBB phenotype in adults, when the ligands are glial derived.

\section{Regulation of the BBB by Pericytes}

Analysis of mouse mutants in PDGFBBPDGFR- $\beta$ signaling has identified an important role for PCs in regulating $\mathrm{BBB}$ formation and function (Armulik et al. 2010; Daneman et al. 2010b). These mutant mouse models include Pdgfb null and Pdgfrb null mice that completely lack CNS PCs and die at birth, as well as extracellular matrix (ECM)-retention motif mutations to Pdgfb or hypomorphic alleles of Pdgfrb in which mice have fewer PCs than their wildtype littermates. Analysis of the BBB in Pdgfrb null mice during embryogenesis revealed a leaky $\mathrm{BBB}$, demonstrating that $\mathrm{PCs}$ are required to regulate the formation of the $\mathrm{BBB}$. In particular, lack of PCs leads to an increase in the rate of transcytosis and an increase in the expression of LAMs resulting in CNS-immune infiltration (Armulik et al. 2010; Daneman et al. 2010b). Further use of mice with Pdgfrb hypomorphic alleles, which have varying numbers of CNS PCs, showed that the total number is important for the relative permeability of the vessels ( $\mathrm{Ar}$ mulik et al. 2010; Daneman et al. 2010b). Additionally, work done in adult mice with ECMretention motif mutations to Pdgfb that contain fewer PCs has identified that PCs are required during adulthood to regulate $\mathrm{BBB}$ homeostasis, and particularly do so by inhibiting transcytosis (Armulik et al. 2010). Microarray analysis comparing the transcriptional profile of CNS ECs with pdgfrb mutant mice and wild-type mice suggest minimal changes in the expression of genes involved in BBB-specific properties, such as tight junctions, nutrient transport, or efflux transport, but an increase in the expression of genes involved in peripheral EC-specific "leaky" properties, including transcytosis (PLVAP) and leukocyte adhesion (Icam1, Alcam) (Daneman et al. 2010b). Taken together, these data suggest that PCs are not involved in the induction of BBB-specific properties (TJs, transporters), but play an important role in the inhibition of properties normally associated with leaky peripheral vessels (transcytosis, LAMs). 
Regulation of the BBB by Astrocytes

The persistence of a functional BBB throughout adulthood is maintained and regulated by numerous factors unique to the microniche of the neurovascular unit (NVU) (Abbott et al. 2006). Astrocyte-BBB-EC interactions are known to regulate EC morphology, angiogenesis, and to influence the phenotype of the barrier under physiological and pathological conditions (Prat et al. 2001).

Astrocytes are known to produce factors that modulate endothelial functioning during development and adulthood. One of these pathways is the Hedgehog $(\mathrm{Hh})$ signaling cascade known to be involved in embryonic morphogenesis, neuronal guidance, and angiogenesis. Astrocytes secrete Sonic Hh (SHh) (Wang et al. 2008), and BBB ECs express the Hh receptor Patched-1, the signal transducer Smoothened (Smo), as well as transcription factors of the Gli family. Interestingly, transendothelial electrical resistance (TEER) and permeability experiments showed that activation of the $\mathrm{Hh}$ pathway induced expression of junctional proteins and promoted a BBB phenotype. In addition, mice genetically engineered to lose the signal transducer Smo on ECs had a significant increase in BBB permeability that correlated with a decrease in junctional protein expression and disturbed BMs (Alvarez et al. 2011a, 2013), supporting the concept that the $\mathrm{Hh}$ pathway has a significant influence on $\mathrm{BBB}$ function.

Astrocytes also secrete angiogenic factors that promote vascular growth, such as vascular endothelial growth factor (VEGF). During development, VEGF is required for the formation, remodeling, and survival of embryonic blood vessels. During early embryogenesis, radial glia cells seem to be the source of VEGF needed for vascular development, although ECs have been described to promote cell-autonomous activation of the VEGF signaling (Lee et al. 2007). Although VEGF is a factor mostly known to promote angiogenesis during development, in adulthood, VEGF decreases the stability of the BBB during inflammatory conditions (Argaw et al. 2009, 2012).
Perivascular cells, including astrocytes, secrete angiopoietins (Ang1), which participate in the complex process of BBB differentiation by promoting angiogenesis and inducing a time-dependent decrease in endothelial permeability. This occurs through the up-regulation of junctional protein expression (Prat et al. 2001). In contrast, Ang-2 is known to participate in the early phases of BBB breakdown during injury and disease (Nourhaghighi et al. 2003). Interestingly, when factors known to compromise BBB function, such as VEGF, are coexpressed with Ang1, the barrier integrity is enhanced and neuroprotective properties are induced (Shen et al. 2011).

Astrocytes also produce the angiotensinconverting enzyme-1 (ACE-1), which converts angiotensin I into angiotensin II and acts on type 1 angiotensin receptors (AT1) expressed by BBB ECs. Angiotensin II induces tightening of vessels, and, in the CNS, activation of AT1 restricts BBB permeability and stabilizes junctional protein function by promoting their recruitment into lipid rafts. Angiotensinogen (AGT)-deficient mice have an aberrant expression of occludin at the BBB, suggesting that astrocyte-secreted angiotensin II promotes TJ formation (Wosik et al. 2007).

TGF- $\beta$ is a pleiomorphic cytokine involved in cell growth, differentiation, morphogenesis, apoptosis, and immunomodulation. In the CNS, TGF- $\beta$ is neuroprotective, and in vitro studies have shown its capacity to induce Mdr1 activity and to reduce BBB permeability (Dohgu et al. 2004). TGF- $\beta$ is secreted by astrocytes and CNS-ECs, and TGF- $\beta$ known to downregulate the extent of leukocyte transmigration across the endothelium. However, the overwhelming pleomorphic roles of TGF- $\beta$ do not currently allow a conclusion on the exact role of astrocyte-derived TGF- $\beta$ in BBB physiology.

Retinoic acid (RA) can be secreted by radial glial cells, and recent findings suggest that RA is also secreted by astrocytes, and its receptor, RAreceptor $\beta$ (RAR- $\beta$ ), is expressed in the developing vasculature. RAR- $\beta$ activation increases TEER, which correlated with enhanced expression of VE-cadherin, P-gp, and ZO-1. In vivo, pharmacologic modulation of RAR- $\beta$ resulted 
in a perturbed BBB (Mizee et al. 2013). Interestingly, RA is known to regulate the $\mathrm{Hh}, \mathrm{Wnt}$, and FGF pathways (Halilagic et al. 2007; Paschaki et al. 2012), which implies that RA secretion by radial glial cells could be a master upstream regulator of $\mathrm{BBB}$ development.

\section{Convergence of Signaling Events at the BBB}

It is clear that the BBB is regulated by a complex set of cellular signaling mechanisms that regulate both the induction of barrier properties during initial angiogenesis into the CNS, as well as the maintenance of barrier properties in adults. Neural stem cells appear to be the key cell type involved in the early differentiation of the ECs into BBB ECs, and then PCs and astrocytes provide further cues modulating the different barrier properties of these CNS ECs. The number of distinct factors that are known to impact on $\mathrm{BBB}$ permeability highlights the diversity of the CNS inputs needed to generate this physiological barrier. This also emphasizes the redundancy of molecular signals affecting BBB formation and stability, and the need for future work to identify how each of these signals are coordinated to regulate different aspects of the BBB. These signals can, however, be integrated into a general concept (Prat et al. 2001). Key signaling pathways and transcription factors have either barrierpromoting properties (Wnt, Hh, Sox-18, nrf2, ERG, Nkx2-1, and SP3/YY1) or barrier-disrupting effects $(\mathrm{NF}-\kappa \mathrm{B}$, Snail, FoxO1, PKC, and eNOS). Within the signaling pathways promoting $\mathrm{BBB}$ functioning, Wnt and Hh seem to be dominant and to cooperate in driving a $\mathrm{BBB}$ phenotype. Wnt ligand binding to Frizzled/ LRP5/ 6 activates $\beta$-catenin, which leads to the expression and targeting of the junctional proteins claudin-3 and p120 to the cell membrane (Liebner et al. 2008; Hong et al. 2010). $\beta$-Catenin also down-regulates the activity of Snail, which has a negative effect on the stability of p120/VE-cadherin complexes and on the expression of TJ molecules occludin and claudin-5. Loss of the Wnt coreceptor Lrp5 causes down-regulation of claudin-5 expression (Chen et al. 2011). The Hh signaling pathway appears to drive the transcription and expression of junctional proteins, but also dampens inflammatory responses on CNS-ECs. Activation of Gli-1 by the Hh ligands or wnt signaling are reported to activate Sox-18 (Alvarez et al. 2011a), which control claudin-5 expression (Fontijn et al. 2008). Wnt and Hh activation also induce the expression of NR2F2, a transcription factor that promotes Ang-1 expression, inducing junctional protein expression through tie-2. NR2F2 also down-regulates expression of Ang-2, a factor known to decrease junctional protein expression. In a similar way, activation of the nrf-2 pathway by oxidative stress activates antioxidant response elements (ARE), which are known to stabilize ZO-1, occludin, and claudin-5 expression (Fan et al. 2013). In addition, nrf-2 protects ECs during injury by supressing the expression of inflammatory genes (Chen et al. 2006). In this sense, signaling pathways and transcription factors supporting barrier function also tend to promote anti-inflammatory responses.

One of the major issues when analyzing previous work is that many different measures have been used to quantify BBB function when analyzing the effect of genetic or environmental perturbations on the barrier, making it difficult to compare and contrast different studies. Furthermore, in many cases, only a small number of measures are used to examine BBB function, whether a single molecular tracer or analysis of a small set of molecular markers. The BBB is not a single entity, but a series of different properties possessed by the CNS ECs and regulated by interactions with different neural, vascular, and immune cells; thus, a more exhaustive approach to understanding how different pathways regulate each aspect of the $\mathrm{BBB}$ is required to fully understand this barrier. Thus, future work needs to identify whether each of these signaling pathways regulate all aspects of the $\mathrm{BBB}$, or whether different properties of the $\mathrm{BBB}$ are induced and regulated by different pathways, and, if so, how do each of these pathways coordinate to regulate the $\mathrm{BBB}$, allowing proper neuronal function. New genetic tools allow for manipulation of genes and pathways both in development and in adulthood and, thus, will be able to determine whether the pathways are required for induction during development, maintenance during 
adulthood, and/or disruption during disease. Furthermore, new intravital imaging techniques in live awake-behaving animals will enable the understanding of how plastic the $\mathrm{BBB}$ is and whether different properties of the BBB can be dynamically regulated in response to neuronal activity, diet, infection, or other environmental stimuli.

\section{DYSFUNCTION OF THE BBB IN CNS DISORDERS}

Disruption of the $\mathrm{BBB}$ is observed in many different neurological disorders including MS, stroke, Alzheimer's disease (AD), epilepsy, and traumatic brain injuries. Functional imaging of human patients and analysis of postmortem brain samples has identified the pathological breakdown of the barrier in different neurological diseases. In addition, work with animal models of disease and with cell culture BBB models has enabled the identification of some of the molecular mechanisms that cause changes to the BBB. This dysfunction can include alterations in many different properties of the BBB including TJs, transporters, transcytosis, and LAM expression. This breakdown can lead to edema, disruption of ionic homeostasis, altered signaling, and immune infiltration that can lead to neuronal dysregulation and, ultimately, degeneration. Although BBB dysfunction is often secondary to the primary insult in these diseases, in some cases, it has been a suggested cause, including MS, epilepsy, and AD (Fig. 3).

\section{MS and Related Disorders}

In most CNS pathologies, the BBB is affected as a result of the inflammation, injury, or degenerative processes specific to the pathology. However, in only a few diseases, the BBB is specifically targeted by the pathogenic process or by the disease determinants. Neuromyelitis optica (NMO) and MS are among these diseases. Astrocytes are generally not regarded as a primary target of the immune system in MS, although $\mathrm{BBB}$ disruption and alterations in astrocyte physiology are hallmarks of MS pathogenesis. The etiology of MS remains elusive, but it is clear that multiple factors are involved in disease development, including environmental and genetic factors. Nevertheless, MS is a T-cellmediated disease in which CD4 T-helper (Th) cells of the Th17 and Th1 phenotype play a fundamental role in its pathogenesis. B cells are also essential in MS immunopathogenesis, as antibodies produced within the CNS are a fundamental feature of the disease (i.e., oligoclonal bands) and as B-cell-directed therapies provide strong protection against lesion formation. It is clear that during immune cell infiltration and lesion formation, BBB function becomes compromised (Larochelle et al. 2011), which is characterized by vascular leakage associated with alterations of junctional proteins. Analysis of MS tissue shows that abnormalities in the expression of junctional proteins coincide with perivascular astrogliosis, and such changes are detected in very early stages of lesion formation (Prat et al. 2001). This has been, in part, explored by Luo et al. (2008) when inducing active experimental autoimmune encephalomyelitis (EAE) in mice expressing luciferase under the control of GFAP. Despite showing clinical signs only at day 11 , increases in bioluminescence associated with GFAP expression could be detected in the brain of these animals as early as $3 \mathrm{~d}$ postinduction suggesting that astrocytes are activated in the very early stages of EAE and in the absence of clinical signs of the disease.

Besides its primary neuroprotective function, the BBB has also been shown to actively promote neuroinflammation by orchestrating immune responses during CNS-targeted autoimmune aggression. BBB ECs are an important source of proinflammatory chemokines CCL2 (Biernacki et al. 2001; Kebir et al. 2007), CCL5, and CXCL10, which are required for lymphocyte and monocyte recruitment to the CNS (Prat et al. 2001). Immune cell infiltration into the CNS correlates with production of proinflammatory mediators, such as interleukin (IL)-17, IL-22, granulocyte macrophage colony-stimulating factor (GM-CSF), interferon (IFN)- $\gamma$, and tumor necrosis factor (TNF) (Alvarez et al. 2011b). These cytokines have been implicated in the modulation of EC function by up-regulating the expression of pro- 
R. Daneman and A. Prat

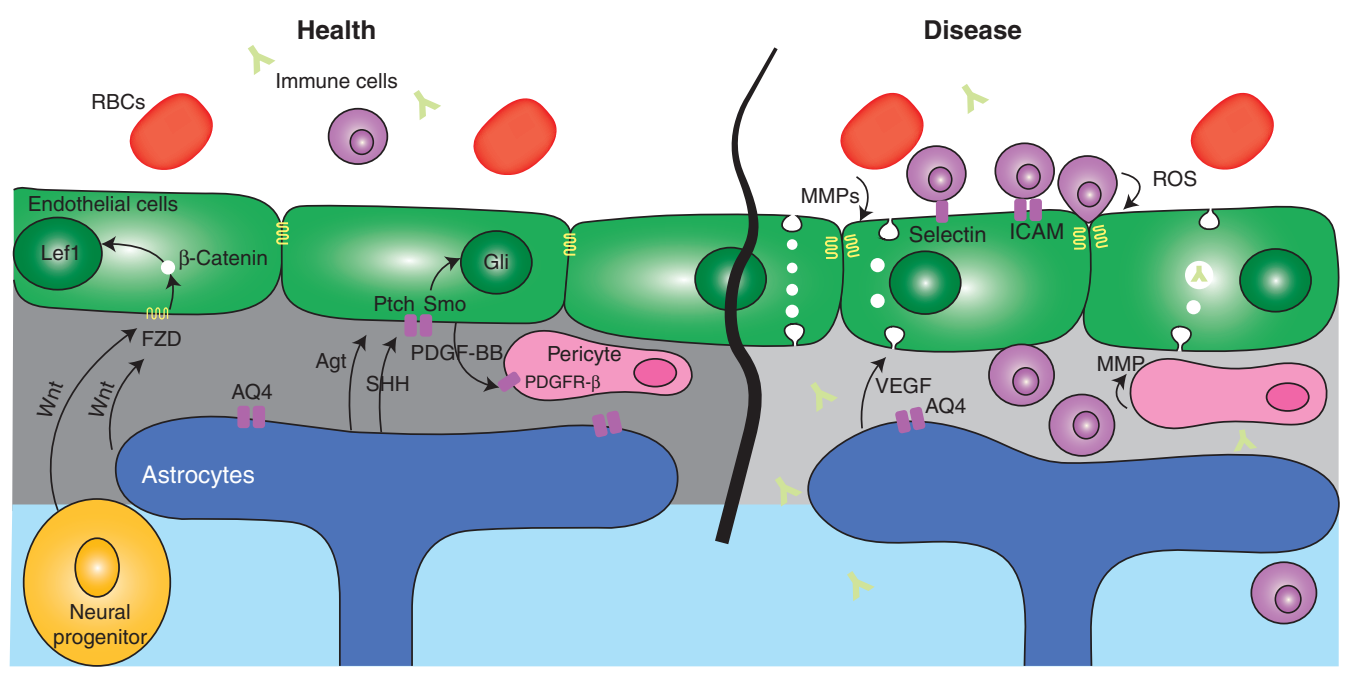

Figure 3. Schematic representation of signaling regulating the blood-brain barrier in health and disease. ICAM, intercellular adhesion molecule; MMP, matrix metalloproteinase; ROS, reactive oxygen species.

inflammatory mediators and by affecting the expression of junctional proteins and, thus, compromising BBB permeability. Last, BBB ECs express intercellular adhesion molecule (ICAM)-1, ICAM-2, vascular CAM (VCAM)1, activated leukocyte CAM (ALCAM), melanoma CAM (MCAM), and Ninjurin-1, which mediate, at least in part, the adhesion process and transmigration of leukocytes and leukocyte subtypes to the CNS (Cayrol et al. 2008; DodeletDevillers et al. 2009; Greenwood et al. 2011). Thus, although the BBB protects against CNSdirected inflammation by restricting immune cell access to the brain, it can also regulate the local inflammatory response by expressing proinflammatory molecules that promote the recruitment of peripheral immune cells into the CNS.

Following migration across ECs, leukocytes cross the endothelial BM and, subsequently, the parenchymal BM to get access into the CNS. The composition of the endothelial BM can regulate the extent of perivascular infiltration as large amounts of leukocytes are detected in vessels expressing laminin 411 and low levels of 511, whereas in the absence of 411, laminin 511 is ubiquitously expressed and associates with low-T-cell infiltration and milder disease. In EAE and MS, immune cell infiltrates are in great part contained to the perivascular space, and the process of leukocyte migration across the parenchymal BM and astrocyte endfeet appears to be more tightly controlled than the diapedesis across ECs (Engelhardt and Sorokin 2009). In EAE, $\mathrm{CD}^{+}{ }^{+} \mathrm{T}$-cell infiltration across the parenchymal $\mathrm{BM}$ is not laminin dependent, but rather requires focal activation of and matrix metalloproteinases (MMP)-2 and MMP-9 to selectively cleave dystroglycan, affecting the BM stability and integrity (Agrawal et al. 2006). Interestingly, parenchymal BM components and other ECM-binding receptors on the astrocyte endfeet remain unaffected, indicating the existence of specific and specialized protective mechanisms under the control of astrocytes and possibly other cells within the NVU (Engelhardt and Sorokin 2009). Thus, further understanding is needed in terms of astrocyte involvement in supporting or inhibiting the activation and migration of immune cells as well as the repair of the affected $\mathrm{BBB} / \mathrm{NVU}$ during MS/ $\mathrm{EAE}$ and other CNS disorders.

Reactive astrocytes can also be the source of factors that will negatively affect barrier function at the NVU. In MS and EAE, VEGF-A is expressed by reactive astrocytes, and in vitro/ in vivo studies show its capacity to induce BBB breakdown by disrupting claudin -5 and 
occludin expression and promote immune cell infiltration to the CNS. Additional studies propose that IL-1 production by microglia induces VEGF-A up-regulation. VEGF-A is released from the astrocytes and binding to its receptor VEGFR2 on BBB-ECs activates eNOS-dependant down-regulation of the junctional proteins claudin-5 and occludin that leads to BBB breakdown.

Although reactive astrocytes can produce BBB-promoting (i.e., $\mathrm{Hh}$ ) or BBB-disrupting (i.e., VEGF) factors, they can also lose or down-regulate factors that have the capacity to promote barrier function. In this regard, astrocytes produce AGT (which is cleaved into angiotensin II), and analysis of MS tissues showed that expression of AGT in astrocytes and occludin in ECs is decreased in MS lesions when compared to normal appearing white matter. This pattern correlates with the down-regulated expression of AGT detected in astrocytes stimulated in vitro with IFN- $\gamma$ and TNF- $\alpha$. Interestingly, nonimmunized (non-EAE) AGT-deficient mice have compromised BBB function, which correlates with decreased and disrupted expression of occludin. Therefore, local inflammatory mediators present in perivascular cuffs can also negatively impact on the capacity of reactive astrocytes to promote $\mathrm{BBB}$ function by down-regulating their production of BBBpromoting factors (Wosik et al. 2007).

$\mathrm{NMO}$ is also an immune-mediated disease of the CNS affecting predominantly the spinal cord and the optic nerves. In NMO, the production of anti-AQP4 IgG antibodies affects the function of the astrocyte water channel AQP4 directly affecting BBB function. Binding of antiAQP4 antibodies to their target results in the activation of complement-dependent cytotoxic cell damage that leads to the loss of AQP4, GFAP, and the excitatory amino-acid transporter 2 (EAAT2). In addition, the BBB damage is associated with focal areas of perivascular immune cell infiltration and demyelination, particularly granulocytes, and eosinophils that degranulate in the perivascular space causing local damage that includes astrocyte injury. Although oligodendrocytes are affected as a result of the pathophysiological changes, the exact mecha- nism(s) leading to oligodendrocyte and neuronal damage remains to be determined.

Modulation of the BBB following Hypoxia/ Ischemia and in Stroke

In vivo and in vitro stroke models have shown that cerebral vascular permeability increases in a time- and hypoxia-dependent manner. This leads to a subsequent increase in cerebral edema; however, the processes involved in the hypoxia-induced BBB permeability are not completely understood. Work in animal models of stroke has identified that there is a biphasic leakage of the BBB, with an early opening within hours following hypoxia/ischemia, followed by a refractory phase and then a second opening the next day (Kuroiwa et al. 1985; Huang et al. 1999). In addition, analysis in transgenic models has identified that there are stepwise alterations in the BBB, with an increase in transcytosis observed first followed by alterations in the TJs (Knowland et al. 2014). There are also important changes in ion channel and efflux transporter expression and activity.

Focal cerebral ischemia damages elements of the BBB and induces inflammatory processes that alter the relationships of ECs, ECM, and astroglial cells. This results in profound changes in the microvascular permeability barrier. Focal increases in permeability to fibrinogen, IgG, and other large proteins are detected within a few hours following middle cerebral artery occlusion (MCAO). Conversely, and surprisingly, hypoxic conditions induce expression of ZO-1 in vitro and claudin -5 and occludin in vivo. The exact functional consequences of these up-regulations are not clear. Nevertheless, levels of ECexpressed integrins $\alpha 1 \beta 1, \alpha 3 \beta 1$, and $\alpha 6 \beta 1$ decrease rapidly after MCAO and MMPs are activated on ischemic insult, which induces basal lamina remodeling, and also chemokine activation. Finally, dystroglycan, expressed by astrocyte, disappears after MCAO, a phenomenon responsible for detachment of astrocyte endfeet and perivascular edema. These studies suggest that adhesive interactions between the endothelium and the ECM contribute to the acute vascular remodeling seen in stroke. 


\section{Molecular Alterations of the Tight Junctions}

Clinically, strokes are known to cause an increase in vasogenic edema, which can be attributed to an increase in BBB permeability. Recent in vitro studies have begun to elucidate the molecular changes leading to increases in BBB permeability. In studies by Mark and Davis (2002) and Witt et al. (2008), an increase in actin protein levels and actin stress fibers was observed following hypoxic insult, whereas hypoxia alone had no effect on protein expression of the TJs, occludin, claudin-1, or ZO-1/2. Following hypoxia, reoxygenation increases expression of occludin, claudin-1, and ZO-1/2 Changes in the cellular localization of the TJ proteins occludin and ZO-1/2 following hypoxic insult were confirmed with dynamic confocal microscopy recordings. Interestingly, these changes were reversible and returned to control levels on reoxygenation.

Changes in junctional structure formation or stability are now known to involve up-regulation in vascular endothelial growth factor (VEGF), and inhibition of VEGF attenuates the hypoxia-induced increase in $\mathrm{BBB}$ permeability (Fischer et al. 2002; Schoch et al. 2002). In addition, hypoxia increases nitric oxide (NO) release by ECs and inhibition of NO synthase reduces the effect of hypoxia on cell permeability. Although the exact mechanisms involved in the VEGF- and NO-mediated changes in EC permeability are still being investigated, some reports have shown that NO may directly modify the TJ proteins by nitrosylation or nitrosation.

\section{MMPs and the $B B B$}

MMPs are zinc-dependent proteases that have the ability to degrade fibronectin and laminins. As the basal lamina is composed of collagen, fibronectin, laminin, and heparin sulfate, and serves as an important scaffold for brain ECs, MMPs have been considered as obvious initiators of BBB disruption. Following ischemia/reperfusion, MMPs have been shown to be upregulated in the brain (Lenglet et al. 2014), either through proinflammatory cytokine pathways (via NF- $\mathrm{KB}$ ) or through activation of HIF-1 $\alpha$ and furin, which convert pro-MT-MMP into activated MT-MMP. More specifically, it has been shown that MMP-9, MMP-3, and MMP2 levels were increased following ischemia/reperfusion, correlating with the increase in sucrose diffusion across the BBB. Additionally, inhibition of MMP with pharmacological agents or use of MMP knockout animals reduced BBB disruption (Rosenberg et al. 1998). It remains unclear whether MMP-mediated BBB disruption occurs at the level of the basal lamina, or at the level of the TJ and AJ, as these junctional proteins were also shown to be substrates of MMPs.

\section{Modulation of Channels and Transporters}

Ion channels and transporters are key components of the $\mathrm{BBB}$, which maintain cerebral physiological and metabolic homeostasis. As one of the major consequences of stroke is the formation of cerebral vasogenic and cytotoxic edema, understanding the effect of stroke on the function of channels and transporters at the BBB could identify important therapeutic targets.

During ischemic stroke, there is an important release of glutamate from neurons that bind to $N$-methyl-D-aspartate (NMDA) receptors. This excess NMDA receptor activation is largely responsible for cytotoxic edema of neurons (Sharp et al. 2003). Studies have shown that BBB ECs also express both NMDA and metabotropic glutamate receptors (Krizbai et al. 1998; Sharp et al. 2003). Circulating inflammatory mediators have also been shown to stimulate a release of glutamate, which disrupts the $\mathrm{BBB}$ via metabotropic receptors (Collard et al. 2002). Interestingly, in vitro studies showed that NMDA receptor activation reduces $\mathrm{BBB}$ integrity, whereas activation of metabotropic receptors increased $\mathrm{BBB}$ electrical resistance suggesting a tightening of the $\mathrm{BBB}$.

The activity of exchangers and transporters, such as the $\mathrm{Na}^{+} / \mathrm{H}^{+}$exchanger (NHE), $\mathrm{Na}^{+} /$ $\mathrm{K}^{+}$ATPase, and $\mathrm{Na}^{+} / \mathrm{K}^{+} / \mathrm{Cl}^{-}$cotransporter, contribute to maintaining ion balance at the $\mathrm{BBB}$ and in the brain in general. During stroke, 
osmotic and ion balance are altered, leading to activation of ion transporters and exchangers.

\section{Regulation of the BBB in AD}

Dysfunction of cerebral vascular ECs and leukocyte transmigration across the $\mathrm{BBB}$ probably participate in the development of $\mathrm{AD}$, Parkinson's disease (PD), and other neurodegenerative diseases. As multidrug resistance function at the level of the BBB decreases with age, decreased clearance of neurotoxic compounds and increased oxidative stress in the brain increases the risk of neurodegenerative pathology.

Arterial spin labeling magnetic resonance imaging (MRI), functional blood-oxygen-level-dependent (BOLD)-MRI, fluorodeoxyglucose-positron emission tomography (FDGPET), and single-photon emission computerized tomography (SPECT) studies in humans show that cerebral blood flow is significantly reduced first in mild cognitive impairment and then in $\mathrm{AD}$. Amyloid $\beta$ is transported from the blood to the brain by the receptor for advanced glycation endproducts (RAGE), which is expressed on BBB-ECs. Conversely, both soluble LRP and ApoE are cell-surface A $\beta$ chaperones that associate with clearance receptors and promote extrusion of $A \beta$ from the brain back into the blood through the $\mathrm{BBB}$. In $\mathrm{AD}$, these clearance pathways seem to be altered, which is hypothesized to lead to accumulation of soluble $\mathrm{A} \beta$ in the perivascular space and the formation of toxic oligomeric $A \beta$. A $\beta$ deposition in the vascular smooth muscle cell layer and $A \beta$ plaque formation around vessels of $\mathrm{AD}$ patients has been well documented, and participate in the pathology of cerebral amyloid angiopathy, an entity strongly linked to AD. Soluble amyloid $\beta$ is also known to stimulate the transmigration of monocytes, to enhance tau pathology, to induce secretion of proinflammatory cytokines (TNF and IL-6) and chemokines, to activate MT1-MMP, the activator of MMP-2, to stimulate production of MMP-9, and to activate production of reactive oxygen species (ROS) when injected by microdialysis in vivo. Patients with $\mathrm{AD}$ have also been reported to have focal vascular defects in the CNS, such as vascular "regres- sion," reduced capillary density, accumulation of collagen, perlecan in the basal lamina, reduced mitochondrial content, and loss of TJ and AJ proteins. These might well be caused by $\mathrm{A} \beta$ accumulation and $\mathrm{BBB}$ dysfunction, although it has not been proven.

\section{Summary}

In addition, BBB disruption has been observed in a series of other neurological diseases including amyotrophic lateral sclerosis (ALS), epilepsy, edema, brain traumas, PD, as well as systemic diseases, such as liver failure (Daneman 2012). A major question remains whether there is a common mechanism for BBB disruption during all different diseases, or whether the dysfunction in each disease results from different cellular and molecular mechanisms. Several different signaling pathways have been shown to be important for $\mathrm{BBB}$ disruption across multiple pathologies including VEGF, reactive oxygen species, TNF- $\alpha$, and MMP-mediated disruption of TJs and ECM, but it remains unknown how different triggers may engage these pathways, and how different outcomes can be observed in different diseases. As with studying $\mathrm{BBB}$ formation, one of the major issues when analyzing studies of $\mathrm{BBB}$ dysfunction is that each study uses different measures of the BBB, thus making it difficult to compare the dysfunction during the disease. What is clear is that disruption of the BBB in many of these diseases appears to be multimodal, with increasing vesicle trafficking, disruption of tight junction strands, and alterations of endothelial transport and metabolic processes. What remains unclear is how each of these processes interacts with each other. For instance, an increase in transcytosis precedes TJ disruption following stroke, but it is not clear whether this increased vesicle trafficking actually leads to the removal of junction proteins and transporters from the cell surface. Furthermore, it remains unclear what the cellular signaling events that coordinate these processes are. Is the $\mathrm{BBB}$ disruption a result of a loss of pericyte and astrocyte signals including Wnt, SHH, and others, or is it because of reception of disruption signals from neural or 
immune cells? In the future, a more exhaustive analysis of the BBB at different stages of each disease as well as large-scale "omics" analysis of changes to the BBB in each disease will clarify this important question.

It is clear that there is BBB dysfunction in many different neurological diseases in a wide variety of species, and, thus, this is an evolutionary conserved important feature of these diseases. A critical question moving forward is to understand what aspects of this BBB dysfunction are healing and what aspects are pathological. Like any inflammatory event, a small amount is likely helpful in clearing debris, fighting pathogens, and aiding in wound healing, whereas a large amount can be debilitating causing tissue dysfunction and degeneration. Thus, understanding the molecular mechanisms regulating BBB breakdown and developing methods to appropriately modulate this process will be critical in developing therapeutics to aid in the repair process of these diseases.

\section{CONCLUSIONS}

The BBB is an important cellular barrier that tightly controls the microenvironment of the CNS to allow for proper neuronal function. This barrier is an extremely important factor to consider when determining treatments for different neurological diseases, both because disruption of the BBB can lead to severe pathology observed in many different diseases, but also because crossing the BBB is an essential consideration in the development of CNS-acting therapeutics. Recent work has identified many molecules required for BBB function as well as many of the cellular and molecular signaling events that regulate the formation of the BBB during development, its function in adulthood, and its response to injury and disease (Fig. 2). Although much progress has been made, many questions still remain. Are all of the different properties of the $\mathrm{BBB}$ regulated by the same pathways or different pathways? How are different signaling pathways coordinated to regulate different aspects of the $\mathrm{BBB}$ ? Which pathways induce properties of the $\mathrm{BBB}$ during development, and which are required throughout life for maintenance of the barrier? How dynamic is the $\mathrm{BBB}$ ? Are different $\mathrm{BBB}$ properties, including the transport and tight junctions, dynamically regulated in response to neural activity? How do alterations in the BBB affect neuronal activity, brain function, and behavior? Are there localized specialties of the BBB that regulate regional neuronal development or function? What leads to loss of BBB properties during neurological disease, a loss of maintenance signals or the presence of disruption signals? Understanding these questions will allow for the development of therapeutics to modulate the $\mathrm{BBB}$ both to restore its function during neurological disease and to develop methods to bypass the BBB for drug delivery (Fig. 3).

\section{REFERENCES}

Abbott NJ, Khan EU, Rollinson CM, Reichel A, Janigro D, Dombrowski SM, Dobbie MS, Begley DJ. 2002. Drug resistance in epilepsy: The role of the blood-brain barrier. Novartis Found Symp 243: 38-47; discussion 47-53, $180-185$.

Abbott NJ, Ronnback L, Hansson E. 2006. Astrocyte-endothelial interactions at the blood-brain barrier. Nat Rev Neurosci 7: 41-53.

Agrawal S, Anderson P, Durbeej M, van Rooijen N, Ivars F, Opdenakker G, Sorokin LM. 2006. Dystroglycan is selectively cleaved at the parenchymal basement membrane at sites of leukocyte extravasation in experimental autoimmune encephalomyelitis. J Exp Med 203: 1007-1019.

Aird WC. 2007a. Phenotypic heterogeneity of the endothelium: II. Representative vascular beds. Circ Res 100: 174190.

Aird WC. 2007b. Phenotypic heterogeneity of the endothelium: I. Structure, function, and mechanisms. Circ Res 100: $158-173$.

Ajami B, Bennett JL, Krieger C, Tetzlaff W, Rossi FM. 2007. Local self-renewal can sustain CNS microglia maintenance and function throughout adult life. Nat Neurosci 10: $1538-1543$.

Alvarez JI, Dodelet-Devillers A, Kebir H, Ifergan I, Fabre PJ, Terouz S, Sabbagh M, Wosik K, Bourbonnière L, Bernard M, et al. 2011a. The Hedgehog pathway promotes blood-brain barrier integrity and CNS immune quiescence. Science 334: 1727-1731.

Alvarez JI, Cayrol R, Prat A. 2011b. Disruption of central nervous system barriers in multiple sclerosis. Biochim Biophys Acta 1812: 252-264.

Alvarez JI, Katayama T, Prat A. 2013. Glial influence on the blood brain barrier. Glia 61: 1939-1958.

Amasheh S, Schmidt T, Mahn M, Florian P, Mankertz J, Tavalali S, Gitter AH, Schulzke JD, Fromm M. 2005. Contribution of claudin- 5 to barrier properties in tight junctions of epithelial cells. Cell Tissue Res 321: 89-96. 
Argaw AT, Gurfein BT, Zhang Y, Zameer A, John GR. 2009. VEGF-mediated disruption of endothelial CLN-5 promotes blood-brain barrier breakdown. Proc Natl Acad Sci 106: 1977-1982.

Argaw AT, Asp L, Zhang J, Navrazhina K, Pham T, Mariani JN, Mahase S, Dutta DJ, Seto J, Kramer EG, et al. 2012. Astrocyte-derived VEGF-A drives blood-brain barrier disruption in CNS inflammatory disease. $J$ Clin Invest 122: $2454-2468$.

Armulik A, Genové G, Mäe M, Nisancioglu MH, Wallgard E, Niaudet C, He L, Norlin J, Lindblom P, Strittmatter K, et al. 2010. Pericytes regulate the blood-brain barrier. $\mathrm{Na}$ ture 468: 557-561

Armulik A, Genové G, Betsholtz C. 2011. Pericytes: Developmental, physiological, and pathological perspectives, problems, and promises. Dev Cell 21: 193-215.

Attwell D, Buchan AM, Charpak S, Lauritzen M, Macvicar BA, Newman EA. 2010. Glial and neuronal control of brain blood flow. Nature 468: 232-243.

Balda MS, Whitney JA, Flores C, González S, Cereijido M, Matter K. 1996. Functional dissociation of paracellular permeability and transepithelial electrical resistance and disruption of the apical-basolateral intramembrane diffusion barrier by expression of a mutant tight junction membrane protein. J Cell Biol 134: 1031-1049.

Betz AL, Goldstein GW. 1978. Polarity of the blood-brain barrier: Neutral amino acid transport into isolated brain capillaries. Science 202: 225-227.

Betz AL, Firth JA, Goldstein GW. 1980. Polarity of the blood-brain barrier: Distribution of enzymes between the luminal and antiluminal membranes of brain capillary endothelial cells. Brain Res 192: 17-28.

Biernacki K, Prat A, Blain M, Antel JP. 2001. Regulation of Th1 and Th2 lymphocyte migration by human adult brain endothelial cells. J Neuropathol Exp Neurol 60: 1127-1136.

Brightman MW, Reese TS. 1969. Junctions between intimately apposed cell membranes in the vertebrate brain. J Cell Biol 40: 648-677.

Cayrol R, Wosik K, Berard JL, Dodelet-Devillers A, Ifergan I, Kebir H, Haqqani AS, Kreymborg K, Krug S, Moumdjian R, et al. 2008. Activated leukocyte cell adhesion molecule promotes leukocyte trafficking into the central nervous system. Nat Immunol 9: 137-145.

Chen XL, Dodd G, Thomas S, Zhang X, Wasserman MA, Rovin BH, Kunsch C. 2006. Activation of Nrf2/ARE pathway protects endothelial cells from oxidant injury and inhibits inflammatory gene expression. Am J Physiol Heart Circ Physiol 290: H1862-H1870.

Chen J, Stahl A, Krah NM, Seaward MR, Dennison RJ, Sapieha P, Hua J, Hatton CJ, Juan AM, Aderman CM, et al. 2011. Wnt signaling mediates pathological vascular growth in proliferative retinopathy. Circulation 124: 1871-1881.

Colegio OR, Van Itallie C, Rahner C, Anderson JM. 2003. Claudin extracellular domains determine paracellular charge selectivity and resistance but not tight junction fibril architecture. Am J Physiol Cell Physiol 284: C1346C1354.

Collard CD, Park KA, Montalto MC, Alapati S, Buras JA, Stahl GL, Colgan SP. 2002. Neutrophil-derived glutamate regulates vascular endothelial barrier function. $J$ Biol Chem 277: 14801-14811.

Conway EM, Carmeliet P. 2004. The diversity of endothelial cells: A challenge for therapeutic angiogenesis. Genome Biol 5: 207.

Coomber BL, Stewart PA. 1985. Morphometric analysis of CNS microvascular endothelium. Microvasc Res 30: 99115.

Cordon-Cardo C, O'Brien JP, Casals D, Rittman-Grauer L, Biedler JL, Melamed MR, Bertino JR. 1989. Multidrugresistance gene (P-glycoprotein) is expressed by endothelial cells at blood-brain barrier sites. Proc Natl Acad Sci 86: 695-698.

Cornford EM, Hyman S, Swartz BE. 1994. The human brain GLUT1 glucose transporter: Ultrastructural localization to the blood-brain barrier endothelia. J Cereb Blood Flow Metab 14: 106-112.

Courtoy PJ, Boyles J. 1983. Fibronectin in the microvasculature: Localization in the pericyte-endothelial interstitium. J Ultrastruct Res 83: 258-273.

Cuevas P, Gutierrez-Diaz JA, Reimers D, Dujovny M, Diaz FG, Ausman JI. 1984. Pericyte endothelial gap junctions in human cerebral capillaries. Anat Embryol (Berl) 170: $155-159$.

Daneman R. 2012. The blood-brain barrier in health and disease. Ann Neurol 72: 648-672.

Daneman R, Agalliu D, Zhou L, Kuhnert F, Kuo CJ, Barres BA. 2009. Wnt $/ \beta$-catenin signaling is required for CNS, but not non-CNS, angiogenesis. Proc Natl Acad Sci 106: 641-646.

Daneman R, Zhou L, Agalliu D, Cahoy JD, Kaushal A, Barres BA. 2010a. The mouse blood-brain barrier transcriptome: A new resource for understanding the development and function of brain endothelial cells. PLOS ONE 5: e13741.

Daneman R, Zhou L, Kebede AA, Barres BA. 2010b. Pericytes are required for blood-brain barrier integrity during embryogenesis. Nature 468: 562-566.

Del Zoppo GJ, Milner R, Mabuchi T, Hung S, Wang X, Koziol JA. 2006. Vascular matrix adhesion and the blood-brain barrier. Biochem Soc Trans 34: 1261-1266.

De Vivo DC, Trifiletti RR, Jacobson RI, Ronen GM, Behmand RA, Harik SI. 1991. Defective glucose transport across the blood-brain barrier as a cause of persistent hypoglycorrhachia, seizures, and developmental delay. N Engl J Med 325: 703-709.

De Vivo DC, Leary L, Wang D. 2002. Glucose transporter 1 deficiency syndrome and other glycolytic defects. J Child Neurol 17: 3S15-3S23; discussion 3S24-3S25.

Diaz-Flores L, Gutiérrez R, Madrid JF, Varela H, Valladares F, Acosta E, Martín-Vasallo P, Díaz-Flores L Jr. 2009. Pericytes. Morphofunction, interactions and pathology in a quiescent and activated mesenchymal cell niche. Histol Histopathol 24: 909-969.

Dodelet-Devillers A, Cayrol R, van Horssen J, Haqqani AS, de Vries HE, Engelhardt B, Greenwood J, Prat A. 2009. Functions of lipid raft membrane microdomains at the blood-brain barrier. J Mol Med (Berl) 87: 765-774.

Dohgu S, Yamauchi A, Takata F, Naito M, Tsuruo T, Higuchi S, Sawada Y, Kataoka Y. 2004. Transforming growth factor- $\beta 1$ upregulates the tight junction and P-glycoprotein 
of brain microvascular endothelial cells. Cell Mol Neurobiol 24: 491-497.

Enerson BE, Drewes LR. 2006. The rat blood-brain barrier transcriptome. J Cereb Blood Flow Metab 26: 959-973.

Engelhardt B. 2008. Immune cell entry into the central nervous system: Involvement of adhesion molecules and chemokines. J Neurol Sci 274: 23-26.

Engelhardt B, Sorokin L. 2009. The blood-brain and the blood-cerebrospinal fluid barriers: Function and dysfunction. Semin Immunopathol 31: 497-511.

Fan X, Staitieh BS, Jensen JS, Mould KJ, Greenberg JA, Josh PC, Koval M, Guidot DM. 2013. Activating the Nrf2mediated antioxidant response element restores barrier function in the alveolar epithelium of HIV-1 transgenic rats. Am J Physiol Lung Cell Mol Physiol 305: L267-L277.

Fischer S, Wobben M, Marti HH, Renz D, Schaper W. 2002. Hypoxia-induced hyperpermeability in brain microvessel endothelial cells involves VEGF-mediated changes in the expression of zonula occludens-1. Microvasc Res 63 : $70-80$.

Fischer S, Wiesnet M, Marti HH, Renz D, Schaper W. 2004. Simultaneous activation of several second messengers in hypoxia-induced hyperpermeability of brain derived endothelial cells. J Cell Physiol 198: 359-369.

Fontijn RD, Volger OL, Fledderus JO, Reijerkerk A, de Vries HE, Horrevoets AJ. 2008. SOX-18 controls endothelialspecific claudin-5 gene expression and barrier function. Am J Physiol Heart Circ Physiol 294: H891-H900.

Furuse M. 2010. Molecular basis of the core structure of tight junctions. Cold Spring Harb Perspect Biol 2: a002907.

Furuse M, Sasaki H, Fujimoto K, Tsukita S. 1998. A single gene product, claudin- 1 or -2 , reconstitutes tight junction strands and recruits occludin in fibroblasts. J Cell Biol 143: 391-401.

Furuse M, Furuse K, Sasaki H, Tsukita S. 2001. Conversion of zonulae occludentes from tight to leaky strand type by introducing claudin-2 into Madin-Darby canine kidney I cells. J Cell Biol 153: 263-272.

Furuse M, Hata M, Furuse K, Yoshida Y, Haratake A, Sugitani Y, Noda T, Kubo A, Tsukita S. 2002. Claudin-based tight junctions are crucial for the mammalian epidermal barrier: A lesson from claudin-1-deficient mice. J Cell Biol 156: 1099-111.

Gerhardt H, Wolburg H, Redies C. 2000. N-cadherin mediates pericytic-endothelial interaction during brain angiogenesis in the chicken. Dev Dyn 218: 472-479.

Ghandour MS, Langley OK, Zhu XL, Waheed A, Sly WS 1992. Carbonic anhydrase IV on brain capillary endothelial cells: A marker associated with the blood-brain barrier. Proc Natl Acad Sci 89: 6823-6827.

Ginhoux F, Greter M, Leboeuf M, Nandi S, See P, Gokhan S, Mehler MF, Conway SJ, Ng LG, Stanley ER, et al. 2010. Fate mapping analysis reveals that adult microglia derive from primitive macrophages. Science 330: 841-845.

Gordon GR, Howarth C, MacVicar BA. 2011. Bidirectional control of arteriole diameter by astrocytes. Exp Physiol 96: 393-399.

Gow A, Southwood CM, Li JS, Pariali M, Riordan GP, Brodie SE, Danias J, Bronstein JM, Kachar B, Lazzarini RA. 1999.
CNS myelin and sertoli cell tight junction strands are absent in Osp/claudin-11 null mice. Cell 99: 649-659.

Greenwood J, Heasman SJ, Alvarez JI, Prat A, Lyck R, Engelhardt B. 2011. Review: Leucocyte-endothelial cell crosstalk at the blood-brain barrier: A prerequisite for successful immune cell entry to the brain. Neuropathol Appl Neurobiol 37: 24-39.

Gu Y, Zheng G, Xu M, Li Y, Chen X, Zhu W, Tong Y, Chung SK, Liu KJ, Shen J. 2012. Caveolin-1 regulates nitric oxide-mediated matrix metalloproteinases activity and blood-brain barrier permeability in focal cerebral ischemia and reperfusion injury. J Neurochem 120: 147-156.

Gupta IR, Ryan AK. 2010. Claudins: Unlocking the code to tight junction function during embryogenesis and in disease. Clin Genet 77: 314-325.

Ha SN, Hochman J, Sheridan RP. 2007. Mini review on molecular modeling of P-glycoprotein (Pgp). Curr Top Med Chem 7: 1525-1529.

Hadj-Rabia S, Baala L, Vabres P, Hamel-Teillac D, Jacquemin E, Fabre M, Lyonnet S, De Prost Y, Munnich A, Hadchouel M, et al. 2004. Claudin-1 gene mutations in neonatal sclerosing cholangitis associated with ichthyosis: A tight junction disease. Gastroenterology 127: 1386-1390.

Halilagic A, Ribes V, Ghyselinck NB, Zile MH, Dollé P, Studer M. 2007. Retinoids control anterior and dorsal properties in the developing forebrain. Dev Biol 303: 362-375.

Hall CN, Reynell C, Gesslein B, Hamilton NB, Mishra A, Sutherland BA, O'Farrell FM, Buchan AM, Lauritzen M, Attwell D. 2014. Capillary pericytes regulate cerebral blood flow in health and disease. Nature 508: 55-60.

Hampson G, Konrad MA, Scoble J. 2008. Familial hypomagnesaemia with hypercalciuria and nephrocalcinosis (FHHNC): Compound heterozygous mutation in the claudin 16 (CLDN16) gene. BMC Nephrol 9: 12.

Henninger DD, Panés J, Eppihimer M, Russell J, Gerritsen M, Anderson DC, Granger DN. 1997. Cytokine-induced VCAM-1 and ICAM-1 expression in different organs of the mouse. J Immunol 158: 1825-1832.

Hickey WF, Kimura H. 1988. Perivascular microglial cells of the CNS are bone marrow-derived and present antigen in vivo. Science 239: 290-292.

Hong JY, Park JI, Cho K, Gu D, Ji H, Artandi SE, McCrea PD. 2010. Shared molecular mechanisms regulate multiple catenin proteins: Canonical Wnt signals and components modulate p120-catenin isoform-1 and additional p120 subfamily members. J Cell Sci 123: 4351-4365.

Hou J, Gomes AS, Paul DL, Goodenough DA. 2006. Study of claudin function by RNA interference. J Biol Chem 281: 36117-36123.

Huang ZG, Xue D, Preston E, Karbalai H, Buchan AM. 1999. Biphasic opening of the blood-brain barrier following transient focal ischemia: Effects of hypothermia. Can J Neurol Sci 26: 298-304.

Huang J, Upadhyay UM, Tamargo RJ. 2006. Inflammation in stroke and focal cerebral ischemia. Surg Neurol 66: 232-245.

Hudson LC, Bragg DC, Tompkins MB, Meeker RB. 2005. Astrocytes and microglia differentially regulate trafficking of lymphocyte subsets across brain endothelial cells. Brain Res 1058: 148-160. 
Janzer RC, Raff MC. 1987. Astrocytes induce blood-brain barrier properties in endothelial cells. Nature 325: $253-$ 257.

Johnson-Leger CA, Aurrand-Lions M, Beltraminelli N, Fase N, Imhof BA. 2002. Junctional adhesion molecule-2 (JAM-2) promotes lymphocyte transendothelial migration. Blood 100: 2479-2486.

Katsimpardi L, Litterman NK, Schein PA, Miller CM, Loffredo FS, Wojtkiewicz GR, Chen JW, Lee RT, Wagers AJ, Rubin LL. 2014. Vascular and neurogenic rejuvenation of the aging mouse brain by young systemic factors. Science 344: $630-634$

Kebir H, Kreymborg K, Ifergan I, Dodelet-Devillers A, Cayrol R, Bernard M, Giuliani F, Arbour N, Becher B, Prat A. 2007. Human TH17 lymphocytes promote blood-brain barrier disruption and central nervous system inflammation. Nat Med 13: 1173-1175.

Keuschnigg J, Henttinen T, Auvinen K, Karikoski M, Salmi M, Jalkanen S. 2009. The prototype endothelial marker PAL-E is a leukocyte trafficking molecule. Blood 114: 478-484.

Knohl SJ, Scheinman SJ. 2004. Inherited hypercalciuric syndromes: Dent's disease (CLC-5) and familial hypomagnesemia with hypercalciuria ( paracellin-1). Semin Nephrol 24: 55-60.

Knowland D, Arac A, Sekiguchi KJ, Hsu M, Lutz SE, Perrino J, Steinberg GK, Barres BA, Nimmerjahn A, Agalliu D. 2014. Stepwise recruitment of transcellular and paracellular pathways underlies blood-brain barrier breakdown in stroke. Neuron 82: 603-617.

Krizbai IA, Deli MA, Pestenácz A, Siklós L, Szabó CA, András I, Joó F. 1998. Expression of glutamate receptors on cultured cerebral endothelial cells. J Neurosci Res 54: 814-819.

Kuroiwa T, Ting P, Martinez H, Klatzo I. 1985. The biphasic opening of the blood-brain barrier to proteins following temporary middle cerebral artery occlusion. Acta Neuropathol 68: 122-129.

Larochelle C, Alvarez JI, Prat A. 2011. How do immune cells overcome the blood-brain barrier in multiple sclerosis? FEBS Lett 585: 3770-3780.

Larsen JM, Martin DR, Byrne ME. 2014. Recent advances in delivery through the blood-brain barrier. Curr Top Med Chem 14: $1148-1160$.

Larson DM, Carson MP, Haudenschild CC. 1987. Junctional transfer of small molecules in cultured bovine brain microvascular endothelial cells and pericytes. Microvasc Res 34: 184-199.

Lee S, Chen TT, Barber CL, Jordan MC, Murdock J, Desai S, Ferrara N, Nagy A, Roos KP, Iruela-Arispe ML. 2007. Autocrine VEGF signaling is required for vascular homeostasis. Cell 130: 691-703.

Lenglet S, Montecucco F, Mach F, Schaller K, Gasche Y, Copin JC. 2014. Analysis of the expression of nine secreted matrix metalloproteinases and their endogenous inhibitors in the brain of mice subjected to ischaemic stroke. Thromb Haemost 112: 363-378.

Li JY, Boado RJ, Pardridge WM. 2001. Blood-brain barrier genomics. J Cereb Blood Flow Metab 21: 61-68.
Li JY, Boado RJ, Pardridge WM. 2002. Rat blood-brain barrier genomics: II. J Cereb Blood Flow Metab 22: 1319-1326.

Liebner S, Corada M, Bangsow T, Babbage J, Taddei A, Czupalla CJ, Reis M, Felici A, Wolburg H, Fruttiger M, et al. 2008. Wnt $/ \beta$-catenin signaling controls development of the blood-brain barrier. J Cell Biol 183: 409-417.

Liu LB, Xue YX, Liu YH. 2010. Bradykinin increases the permeability of the blood-tumor barrier by the caveolae-mediated transcellular pathway. J Neurooncol 99: 187-194.

Loscher W, Potschka H. 2005. Blood-brain barrier active efflux transporters: ATP-binding cassette gene family. NeuroRx 2: 86-98.

Ludwig RJ, Zollner TM, Santoso S, Hardt K, Gille J, Baatz H, Johann PS, Pfeffer J, Radeke HH, Schön MP, et al. 2005. Junctional adhesion molecules (JAM)-B and -C contribute to leukocyte extravasation to the skin and mediate cutaneous inflammation. J Invest Dermatol 125: 969976.

Luo J, Ho P, Steinman L, Wyss-Coray T. 2008. Bioluminescence in vivo imaging of autoimmune encephalomyelitis predicts disease. J Neuroinflammation 5: 6 .

Majesky MW. 2007. Developmental basis of vascular smooth muscle diversity. Arterioscler Thromb Vasc Biol 27: $1248-1258$.

Mark KS, Davis TP. 2002. Cerebral microvascular changes in permeability and tight junctions induced by hypoxia-reoxygenation. Am J Physiol Heart Circ Physiol 282: H1485-H1494.

Martin-Padura I, Lostaglio S, Schneemann M, Williams L, Romano M, Fruscella P, Panzeri C, Stoppacciaro A, Ruco L, Villa A, et al. 1998. Junctional adhesion molecule, a novel member of the immunoglobulin superfamily that distributes at intercellular junctions and modulates monocyte transmigration. J Cell Biol 142: 117-127.

Masuda S, Oda Y, Sasaki H, Ikenouchi J, Higashi T, Akashi M, Nishi E, Furuse M. 2011. LSR defines cell corners for tricellular tight junction formation in epithelial cells. $J$ Cell Sci 124: 548-555.

McCarthy KM, Skare IB, Stankewich MC, Furuse M, Tsukita S, Rogers RA, Lynch RD, Schneeberger EE. 1996. Occludin is a functional component of the tight junction. J Cell Sci 109: 2287-2298.

Mittapalli RK, Manda VK, Adkins CE, Geldenhuys WJ, Lockman PR. 2010. Exploiting nutrient transporters at the blood-brain barrier to improve brain distribution of small molecules. Ther Deliv 1: 775-784.

Miyamoto T, Morita K, Takemoto D, Takeuchi K, Kitano Y, Miyakawa T, Nakayama K, Okamura Y, Sasaki H, Miyachi Y, et al. 2005. Tight junctions in Schwann cells of peripheral myelinated axons: A lesson from claudin-19-deficient mice. J Cell Biol 169: 527-538.

Mizee MR, Wooldrik D, Lakeman KA, van het Hof B, Drexhage JA, Geerts D, Bugiani M, Aronica E, Mebius RE, Prat A, et al. 2013. Retinoic acid induces blood-brain barrier development. J Neurosci 33: 1660-1671.

Morita K, Sasaki H, Furuse M, Tsukita S. 1999. Endothelial claudin: Claudin-5/TMVCF constitutes tight junction strands in endothelial cells. J Cell Biol 147: 185-194. 
Murakami M, Nguyen LT, Zhuang ZW, Moodie KL, Carmeliet P, Stan RV, Simons M. 2008. The FGF system has a key role in regulating vascular integrity. J Clin Invest 118: 3355-3366.

Nitta T, Hata M, Gotoh S, Seo Y, Sasaki H, Hashimoto N, Furuse M, Tsukita S. 2003. Size-selective loosening of the blood-brain barrier in claudin-5-deficient mice. J Cell Biol 161: 653-660.

Noell S, Wolburg-Buchholz K, Mack AF, Beedle AM, Satz JS, Campbell KP, Wolburg H, Fallier-Becker P. 2011. Evidence for a role of dystroglycan regulating the membrane architecture of astroglial endfeet. Eur J Neurosci 33: 2179-2186.

Nourhaghighi N, Teichert-Kuliszewska K, Davis J, Stewart DJ, Nag S. 2003. Altered expression of angiopoietins during blood-brain barrier breakdown and angiogenesis. Lab Invest 83: 1211-1222.

Ohtsuki S, Hirayama M, Ito S, Uchida Y, Tachikawa M, Terasaki T. 2014. Quantitative targeted proteomics for understanding the blood-brain barrier: Towards pharmacoproteomics. Expert Rev Proteomics 11: 303-313.

Oldendorf WH, Cornford ME, Brown WJ. 1977. The large apparent work capability of the blood-brain barrier: A study of the mitochondrial content of capillary endothelial cells in brain and other tissues of the rat. Ann Neurol 1: 409-417.

Orlowski M, Sessa G, Green JP. 1974. $\gamma$-Glutamyl transpeptidase in brain capillaries: Possible site of a blood-brain barrier for amino acids. Science 184: 66-68.

Paschaki M, Lin SC, Wong RL, Finnell RH, Dollé P, Niederreither K. 2012. Retinoic acid-dependent signaling pathways and lineage events in the developing mouse spinal cord. PLoS ONE 7: e32447.

Peppiatt CM, Howarth C, Mobbs P, Attwell D. 2006. Bidirectional control of CNS capillary diameter by pericytes. Nature 443: 700-704.

Persidsky Y, Ghorpade A, Rasmussen J, Limoges J, Liu XJ, Stins M, Fiala M, Way D, Kim KS, Witte MH, et al. 1999. Microglial and astrocyte chemokines regulate monocyte migration through the blood-brain barrier in human immunodeficiency virus-1 encephalitis. Am J Pathol 155: 1599-1611.

Polfliet MM, Zwijnenburg PJ, van Furth AM, van der Poll T, Döpp EA, Renardel de Lavalette C, van Kesteren-Hendrikx EM, van Rooijen N, Dijkstra CD, van den Berg TK. 2001. Meningeal and perivascular macrophages of the central nervous system play a protective role during bacterial meningitis. J Immunol 167: 4644-4650.

Potschka H, Fedrowitz M, Loscher W. 2001. P-glycoprotein and multidrug resistance-associated protein are involved in the regulation of extracellular levels of the major antiepileptic drug carbamazepine in the brain. Neuroreport 12: 3557-3560.

Prat A, Biernacki K, Wosik K, Antel JP. 2001. Glial cell influence on the human blood-brain barrier. Glia 36: 145-155.

Reese TS, Karnovsky MJ. 1967. Fine structural localization of a blood-brain barrier to exogenous peroxidase. J Cell Biol 34: 207-217.

Reuss B, Dono R, Unsicker K. 2003. Functions of fibroblast growth factor (FGF)-2 and FGF-5 in astroglial differen- tiation and blood-brain barrier permeability: Evidence from mouse mutants. J Neurosci 23: 6404-6412.

Rosenberg GA, Estrada EY, Dencoff JE. 1998. Matrix metalloproteinases and TIMPs are associated with bloodbrain barrier opening after reperfusion in rat brain. Stroke 29: 2189-2195.

Saitou M, Furuse M, Sasaki H, Schulzke JD, Fromm M, Takano H, Noda T, Tsukita S. 2000. Complex phenotype of mice lacking occludin, a component of tight junction strands. Mol Biol Cell 11: 4131-4142.

Schinkel AH, Smit JJ, van Tellingen O, Beijnen JH, Wagenaar E, van Deemter L, Mol CA, van der Valk MA, RobanusMaandag EC, te Riele HP, et al. 1994. Disruption of the mouse $m d r 1 a$ P-glycoprotein gene leads to a deficiency in the blood-brain barrier and to increased sensitivity to drugs. Cell 77: 491-502.

Schinkel AH, Wagenaar E, van Deemter L, Mol CA, Borst P. 1995. Absence of the mdrla P-Glycoprotein in mice affects tissue distribution and pharmacokinetics of dexamethasone, digoxin, and cyclosporin A. J Clin Invest 96: $1698-1705$.

Schinkel AH, Wagenaar E, Mol CA, van Deemter L. 1996. Pglycoprotein in the blood-brain barrier of mice influences the brain penetration and pharmacological activity of many drugs. J Clin Invest 97: 2517-2524.

Schoch HJ, Fischer S, Marti HH. 2002. Hypoxia-induced vascular endothelial growth factor expression causes vascular leakage in the brain. Brain 125: 2549-2557.

Sharp CD, Hines I, Houghton J, Warren A, Jackson TH IV, Jawahar A, Nanda A, Elrod JW, Long A, Chi A, et al. 2003. Glutamate causes a loss in human cerebral endothelial barrier integrity through activation of NMDA receptor. Am J Physiol Heart Circ Physiol 285: H2592-H2598.

Shen F, Walker EJ, Jiang L, Degos V, Li J, Sun B, Heriyanto F, Young WL, Su H. 2011. Coexpression of angiopoietin-1 with VEGF increases the structural integrity of the blood-brain barrier and reduces atrophy volume. J Cereb Blood Flow Metab 31: 2343-2351.

Shepro D, Morel NM. 1993. Pericyte physiology. FASEB J 7: 1031-1038.

Shue EH, Carson-Walter EB, Liu Y, Winans BN, Ali ZS, Chen J, Walter KA. 2008. Plasmalemmal vesicle associated protein-1 (PV-1) is a marker of blood-brain barrier disruption in rodent models. BMC Neurosci 9: 29.

Sims DE. 1986. The pericyte-A review. Tissue Cell 18: 153174.

Sorokin L. 2010. The impact of the extracellular matrix on inflammation. Nat Rev Immunol 10: 712-723.

Stenman JM, Rajagopal J, Carroll TJ, Ishibashi M, McMahon J, McMahon AP. 2008. Canonical Wnt signaling regulates organ-specific assembly and differentiation of CNS vasculature. Science 322: 1247-1250.

Stewart PA, Wiley MJ. 1981. Developing nervous tissue induces formation of blood-brain barrier characteristics in invading endothelial cells: A study using quail-chick transplantation chimeras. Dev Biol 84: 183-192.

Streit WJ, Conde JR, Fendrick SE, Flanary BE, Mariani CL. 2005. Role of microglia in the central nervous system's immune response. Neurol Res 27: 685-691.

Thiebaut F, Tsuruo T, Hamada H, Gottesman MM, Pastan I, Willingham MC. 1989. Immunohistochemical localiza- 
tion in normal tissues of different epitopes in the multidrug transport protein P170: Evidence for localization in brain capillaries and crossreactivity of one antibody with a muscle protein. J Histochem Cytochem 37: 159-164.

Ufnal M, Skrzypecki J. 2014. Blood borne hormones in a cross-talk between peripheral and brain mechanisms regulating blood pressure, the role of circumventricular organs. Neuropeptides 48: 65-73.

Unger ER, Sung JH, Manivel JC, Chenggis ML, Blazar BR, Krivit W. 1993. Male donor-derived cells in the brains of female sex-mismatched bone marrow transplant recipients: A Y-chromosome specific in situ hybridization study. J Neuropathol Exp Neurol 52: 460-470.

Van Itallie CM, Anderson JM. 2006. Claudins and epithelial paracellular transport. Annu Rev Physiol 68: 403-429.

Van Itallie CM, Anderson JM. 2013. Claudin interactions in and out of the tight junction. Tissue Barriers 1: e25247.

Van Itallie C, Rahner C, Anderson JM. 2001. Regulated expression of claudin- 4 decreases paracellular conductance through a selective decrease in sodium permeability. $J$ Clin Invest 107: 1319-1327.

Van Itallie CM, Holmes J, Bridges A, Gookin JL, Coccaro MR, Proctor W, Colegio OR, Anderson JM. 2008. The density of small tight junction pores varies among cell types and is increased by expression of claudin-2. J Cell Sci 121: 298-305.

Vass K, Hickey WF, Schmidt RE, Lassmann H. 1993. Bone marrow-derived elements in the peripheral nervous system. An immunohistochemical and ultrastructural investigation in chimeric rats. Lab Invest 69: 275-282.

Villeda SA, Luo J, Mosher KI, Zou B, Britschgi M, Bieri G, Stan TM, Fainberg N, Ding Z, Eggel A, et al. 2011. The ageing systemic milieu negatively regulates neurogenesis and cognitive function. Nature 477: 90-94.

Villeda SA, Plambeck KE, Middeldorp J, Castellano JM, Mosher KI, Luo J, Smith LK, Bieri G, Lin K, Berdnik D, et al. 2014. Young blood reverses age-related impairments in cognitive function and synaptic plasticity in mice. Nat Med 20: 659-663.

Wang Y, Imitola J, Rasmussen S, O'Connor KC, Khoury SJ. 2008. Paradoxical dysregulation of the neural stem cell pathway Sonic Hedgehog-Glil in autoimmune encephalomyelitis and multiple sclerosis. Ann Neurol 64: 417-427.

Wang Y, Rattner A, Zhou Y, Williams J, Smallwood PM, Nathans J. 2012. Norrin/Frizzled4 signaling in retinal vascular development and blood brain barrier plasticity. Cell 151: 1332-1344.
Westergaard E, Brightman MW. 1973. Transport of proteins across normal cerebral arterioles. J Comp Neurol 152: 1744.

Williams K, Alvarez X, Lackner AA. 2001. Central nervous system perivascular cells are immunoregulatory cells that connect the CNS with the peripheral immune system. Glia 36: 156-164.

Witt KA, Mark KS, Sandoval KE, Davis TP. 2008. Reoxygenation stress on blood-brain barrier paracellular permeability and edema in the rat. Microvasc Res 75: 91-96.

Wolburg H, Wolburg-Buchholz K, Fallier-Becker P, Noell S, Mack AF. 2011. Structure and functions of aquaporin-4based orthogonal arrays of particles. Int Rev Cell Mol Biol 287: $1-41$.

Wong V, Gumbiner BM. 1997. A synthetic peptide corresponding to the extracellular domain of occludin perturbs the tight junction permeability barrier. J Cell Biol 136: 399-409.

Wosik K, Cayrol R, Dodelet-Devillers A, Berthelet F, Bernard M, Moumdjian R, Bouthillier A, Reudelhuber TL, Prat A. 2007. Angiotensin II controls occludin function and is required for blood brain barrier maintenance: Relevance to multiple sclerosis. J Neurosci 27: $9032-$ 9042.

Wu C, Ivars F, Anderson P, Hallmann R, Vestweber D, Nilsson P, Robenek H, Tryggvason K, Song J, Korpos E, et al. 2009. Endothelial basement membrane laminin $\alpha 5$ selectively inhibits $\mathrm{T}$ lymphocyte extravasation into the brain. Nat Med 15: 519-527.

Xu Q, Wang Y, Dabdoub A, Smallwood PM, Williams J, Woods C, Kelley MW, Jiang L, Tasman W, Zhang K, et al. 2004. Vascular development in the retina and inner ear: Control by Norrin and Frizzled-4, a high-affinity ligand-receptor pair. Cell 116: 883-895.

Ye X, Wang Y, Nathans J. 2010. The Norrin/Frizzled4 signaling pathway in retinal vascular development and disease. Trends Mol Med 16: 417-425.

Yuan SY. 2002. Protein kinase signaling in the modulation of microvascular permeability. Vascul Pharmacol 39: 213-223.

Zhao LN, Yang ZH, Liu YH, Ying HQ, Zhang H, Xue YX. 2011. Vascular endothelial growth factor increases permeability of the blood-tumor barrier via caveolae-mediated transcellular pathway. J Mol Neurosci 44: 122-129.

Zlokovic BV. 2008. The blood-brain barrier in health and chronic neurodegenerative disorders. Neuron 57: 178201. 


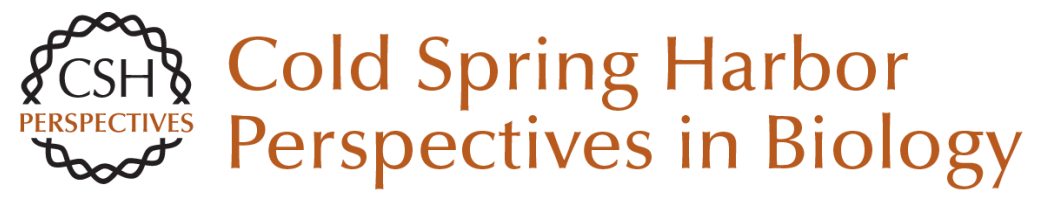

\section{The Blood-Brain Barrier}

Richard Daneman and Alexandre Prat

Cold Spring Harb Perspect Biol 2015; doi: 10.1101/cshperspect.a020412

Subject Collection Glia

The Nodes of Ranvier: Molecular Assembly and Maintenance

Matthew N. Rasband and Elior Peles

Microglia in Health and Disease

Richard M. Ransohoff and Joseph El Khoury

The Astrocyte: Powerhouse and Recycling Center Bruno Weber and L. Felipe Barros

Microglia Function in Central Nervous System

Development and Plasticity

Dorothy P. Schafer and Beth Stevens

Transcriptional and Epigenetic Regulation of

Oligodendrocyte Development and Myelination in

the Central Nervous System

Ben Emery and Q. Richard Lu

Origin of Microglia: Current Concepts and Past

Controversies

Florent Ginhoux and Marco Prinz

Glia Disease and Repair--Remyelination

Robin J.M. Franklin and Steven A. Goldman

Astrocytes in Neurodegenerative Disease

Hemali Phatnani and Tom Maniatis
Oligodendrocyte Development and Plasticity Dwight E. Bergles and William D. Richardson

Oligodendrocytes: Myelination and Axonal

Support Mikael Simons and Klaus-Armin Nave

Drosophila Central Nervous System Glia Marc R. Freeman

Perisynaptic Schwann Cells at the Neuromuscular Synapse: Adaptable, Multitasking Glial Cells Chien-Ping Ko and Richard Robitaille

Astrocytes Control Synapse Formation, Function, and Elimination

Won-Suk Chung, Nicola J. Allen and Cagla Eroglu

Schwann Cell Myelination James L. Salzer

Schwann Cells: Development and Role in Nerve Repair Kristján R. Jessen, Rhona Mirsky and Alison C. Lloyd

Perineurial Glia

Sarah Kucenas

For additional articles in this collection, see http://cshperspectives.cshlp.org/cgi/collection/

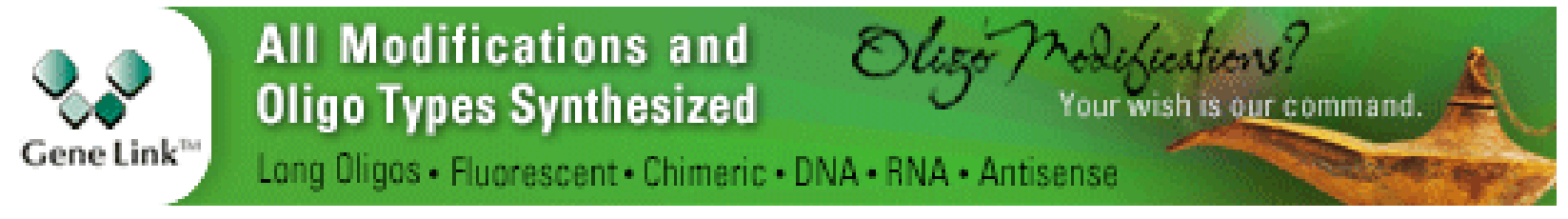

Copyright @ 2015 Cold Spring Harbor Laboratory Press; all rights reserved 